\title{
Animal models of drug addiction: Where do we go from here?
}

\author{
Mary C. Olmstead \\ Queen's University, Kingston, Ontario, Canada
}

\begin{abstract}
Compulsion and impulsivity are both primary features of drug addiction. Based on decades of animal research, we have a detailed understanding of the factors (both environmental and physiological) that influence compulsive drug use, but still know relatively little about the impulsive aspects of drug addiction. This review outlines our current knowledge of the relationship between impulsivity and drug addiction, focusing on cognitive and motor impulsivity, which are particularly relevant to this disorder. Topics to be discussed include the influence of chronic drug administration on impulsivity, the mechanisms that may explain drug-induced impulsivity, and the role of individual differences in the development of impulsive drug use. In addition, the manner in which contemporary theories of drug addiction conceptualize the relationship between impulsivity and compulsion is examined. Most importantly, this review emphasizes a critical role for animal research in understanding the role of impulsivity in the development and maintenance of drug addiction.
\end{abstract}

Drug addiction is a lay term that refers to maladaptive drug use and an obsession with securing and consuming the drug. The more specific medical terms substance abuse and substance dependence (American Psychiatric Association, 1994) include diagnostic criteria such as repeated, unsuccessful attempts to stop using the drug, disruption of personal activities due to drug use, consuming drugs in larger amounts or over longer periods than was intended, and continued drug use despite knowledge of adverse consequences. Although drug tolerance and withdrawal often occur with these symptoms, they are not necessary features of either substance dependence or substance abuse. Both lay and medical definitions, therefore, emphasize two distinct and defining behavioural traits of addiction: compulsion to take the drug and loss of control in limiting drug intake (Koob \& Le Moal, 2001).

\section{Behavioural traits of drug addiction}

\section{Compulsion}

Compulsive drug use in humans is associated with craving, which reflects the desire to reexperience the psychoactive effects of a drug (Markou et al., 1993). Despite the difficulty of assessing affective processes in nonhumans, most researchers agree

Correspondence should be addressed to Mary C. Olmstead, Department of Psychology, Queen's University, 62 Arch Street, Kingston, ON, K7L 3N6, Canada. Email: olmstead@post.queensu.ca

This work was supported by grants from the Natural Sciences and Engineering Research Council of Canada and the Advisory Research Council of Queen's University. I thank Richard Beninger and an anonymous reviewer for helpful comments on this manuscript. I am particularly indebted to Iris Balodis, Stephanie Hancock, Kim Hellemans, Catherine Ortner, Tracie Paine, and Jay Paquette for our theoretical discussions and for conducting the experiments that are reported in this paper. 
that drug seeking provides a quantifiable measure of craving in laboratory animals. Second-order or progressive ratio schedules of reinforcement provide ideal opportunities to measure drug seeking in that both institute high response requirements for a single presentation of the reinforcer. Although employed less frequently, choice responding under concurrent schedules of reinforcement may provide valuable insight into drug seeking because the impact of alternative (i.e., competing) reinforcers, and the work required to obtain each, can be measured simultaneously. Some researchers describe the preference for an environment previously associated with a drug injection (i.e., a conditioned place preference) as drug seeking, but this measure lacks construct validity to the human condition of craving. That is, time in the drug-paired compartment provides no indication of how hard animals will work to obtain the drug. More importantly, none of these measures dissociate drug seeking (i.e., craving) from drug taking (i.e., selfadministration), despite evidence that the two processes are mediated by distinct mechanisms (Robinson \& Berridge, 1993).

In order to address this issue, we developed a novel paradigm in which animals respond for drug under a heterogeneous chain schedule: drug-seeking responses give access to a drugtaking lever (Olmstead, Parkinson, Miles, Everitt, \& Dickinson, 2000). The fact that drug seeking and drug taking are differentially affected by dose, time-out period (Olmstead et al., 2000), and duration of opiate abstinence (Hellemans, Shaham, \& Olmstead, 2002) confirms that the two measures are independent. This paradigm provided the means to examine psychological mechanisms that mediate drug seeking in rats (Hutcheson, Everitt, Robbins, \& Dickinson, 2001; Olmstead, Lafond, Everitt, \& Dickinson, 2001; Vanderschuren \& Everitt, 2004). One of the most interesting findings is that extended experience with cocaine self-administration decreases the ability of an aversive cue to suppress cocaine seeking (Vanderschuren \& Everitt, 2004). The implication of this work is that compulsive drug use reflects an insensitivity to adverse outcomes associated with drug intake. Importantly, the study ruled out altered reward sensitivity as an explanation for changes in drug seeking. Compulsive drug seeking, therefore, may reflect the development of habitual responding (Tiffany, 1990), particularly as cocaine seeking in this paradigm is goal directed (i.e., mediated by a response-outcome association) when access to the drug is limited (Olmstead et al., 2001).

At the same time, chronic drug administration clearly alters brain reward systems, which may contribute to enhanced drug seeking in other paradigms or situations (Babe \& Serafin, 1996; Everitt, Dickinson, \& Robbins, 2001; Robinson \& Berridge, 1993; Wise, 1988). In addition, environmental factors such as conditioned cues (Everitt \& Robbins, 2000) and stress (Marinelli \& Piazza, 2002; Shaham, Erb, \& Stewart, 2000) have a profound impact on drug seeking, and these effects interact with drug experience. Thus, thorough and intensive animal research over the last 20 years suggests that compulsive drug use is due to some combination of habitual responding, altered reward sensitivity, disruptions in learning, and altered responses to stress.

If this is true, compulsion in drug addiction must be mediated through multiple brain sites. Most researchers agree that altered reward sensitivity is associated with changes in the mesolimbic dopamine (DA) system (Everitt et al., 2001; Robinson \& Berridge, 1993; Wise, 1988), manifested at the molecular level (Nestler, 2001). In contrast, the development of habitual responding probably reflects a contribution of the dorsolateral striatum (Yin, Knowlton, \& Balleine, 2004). Given that abused drugs share the common feature of enhancing DA release in striatal regions (Wise \& Bozarth, 1987), repeated drug administration could increase both the incentive value of drugs and the development of stimulusbound behaviour (N. M. White, 1996). The control of behaviour by conditioned drug cues occurs through interactions with the basolateral amygdala and mesolimbic DA system (Everitt et al., 1999), whereas stress-induced alterations in drug seeking are mediated through

\section{THE QUARTERLY JOURNAL OF EXPERIMENTAL PSYCHOLOGY, 2006, 59 (4)}


corticotrophin releasing factor in the bed nucleus of the stria terminalis (Shaham et al., 2000).

\section{Impulsivity}

In contrast to this extensive and thorough knowledge of the behavioural and neurobiological factors that contribute to compulsive drug use, relatively little is known about the loss of inhibitory control in drug addiction. Five years ago, Leshner (2000) pointed out that "determining whether there are biological explanations for behavioural disinhibition requires further investigation". Despite this, in a subsequent series of reviews on drug addiction (Journal of Neuroscience, 2002, Vol. 22) none of the seven papers discussed behavioural disinhibition, and most did not mention it.

Disinhibition is one aspect of impulsivity, which itself is a multifactorial construct encompassing several different processes (Evenden, 1999). These include the inability to delay gratification, the inability to withhold a response, acting before all of the relevant information is provided, and decision making that is inappropriate, risky, or generally ill conceived. Drug addicts consistently choose the immediate rewards of intoxication over the long-term rewards of abstinence and are unable to refrain from further drug taking, particularly when they are in a druginduced state. The two aspects of impulsivity that are most relevant for the study of addiction, therefore, are delay of gratification and an inability to withhold a response; these are often referred to as cognitive and motor impulsivity, respectively (Brunner \& Hen, 1997).

Experimental evidence confirms that drug addicts show a greater tendency to choose small, immediate rewards (drugs or money) over larger, delayed rewards (Kirby, Petry, \& Bickel, 1999; Moeller et al., 2002; Petry, 2001; Vuchinich \& Simpson, 1998), and discount their drug of choice faster than they do monetary rewards of equal value (Madden, Petry, Badger, \& Bickel, 1997). Moreover, some drug addicts show deficits in a gambling task that models the uncertainty of real-life decision making (Bechara \& Damasio, 2002). Fewer studies have examined motor impulsivity in drug addicts, but existing evidence points to increases in perseveration (Bechara et al., 2001; Beatty, Katzung, Moreland, \& Nixon, 1995; Ornstein et al., 2000) and disinhibition (Fillmore \& Rush, 2002). Drug addicts also self-report higher levels of impulsivity on many different personality scales (Moeller et al., 2002; Morgan, 1998; O’Boyle \& Barratt, 1993; von Knorring, von Knorring, Smigan, Lindberg, \& Edholm, 1987), and there is a high rate of substance abuse in clinical populations with impulse control disorders (Lesch \& Merschdorf, 2000). Thus, both trait and state impulsivity are increased in addicts, although the relationship between personality and behavioural measures of impulsivity probably depends on the specific questionnaire (Mitchell, 1999; Richards, Zhang, Mitchell, \& de Wit, 1999b).

In terms of neural mechanisms, both cognitive and motor impulsivity are associated with dysfunction in serotonin (5-HT) and/or prefrontal cortex (PFC) systems. First, reductions in 5-HT activity increase the choice of a small immediate reward over a large delayed reward (Bizot, Le Bihan, Puech, Hamon, \& Thiebot, 1996; Evenden \& Ryan, 1999); 5-HT agonists have the opposite effect (Poulos, Parker, \& Le, 1996). Second, 5-HT depletions increase behavioural disinhibition (Franklin et al., 2002; Roberts, Loh, Baker, \& Vickers, 1994) and premature responding in a reaction time task (Harrison, Everitt, \& Robbins, 1997). The effects of 5-HT agents on cognitive and motor impulsivity appear to be mediated through subtypes of the 5-HT receptor (Evenden, 1998) and specific serotonergic pathways (Fletcher, 1993). Third, disinhibition is particularly notable in frontal lobe patients (Miller, 1992) and in rats following lesions (Weissenborn, Robbins, \& Everitt, 1997; Wilcott, 1982) or DA depletion (Sokolowski \& Salamone, 1994) of the PFC. Finally, cognitive impulsivity may be mediated by subregions of the PFC because destruction of one region (ventromedial PFC) produces an inability to delay gratification (Bechara, Tranel, \& Damasio, 2000), and choosing between small likely and large unlikely rewards activates another (orbitofrontal PFC; Rogers et al., 1999; for alternate 
view, see Cardinal, Pennicott, Sugathapaia, Robbins, \& Everitt, 2001).

Given the co-occurrence of impulsivity and drug addiction, it is not surprising that addicts show abnormalities in 5-HT and PFC systems. These are most common in cocaine addicts and include upregulation of 5-HT transporters in the dorsal raphe (Jacobsen, Staley, Malison, Zoghbi, Seibyl, Kosten, \& Innis, 2000), and increases in 5-HT levels post mortem (Little, Patel, Clark, \& Butts, 1996). As well, increases in monoamine transporters in the orbitofrontal cortex (Little et al., 1998), reductions in grey matter density in orbitofrontal and cingulate cortices (Franklin et al., 2002), and reduced functional activity in the ventromedial PFC (Hommer et al., 1997; London, Ernst, Grant, Bonson, \& Weinstein, 2000; Stapleton et al., 1995; Volkow \& Fowler, 2000) are evident following long-term cocaine use. Structural changes in the PFC of addicts correlate with functional deficits, and both are apparent up to 6 weeks into abstinence (Fein, Di Sclafani, \& Meyerhoff, 2002). Importantly, at least some drug addicts exhibit deficits in a decision-making task known to be sensitive to PFC damage (Bechara \& Damasio, 2002).

The prevalence of both impulse control disorders and neural changes in drug addicts has led to the hypothesis that chronic drug use produces alterations in neural systems that mediate impulsivity, thereby leading to further drug use (Jentsch \& Taylor, 1999; Koob \& Le Moal, 2001). Although a causal relationship is difficult to establish in humans, reductions in 5-HT transporter levels are correlated with lifetime alcohol intake (Heinz, Mann, Weinberger, \& Goldman, 2001), the extent of decision-making deficit in stimulant abusers is correlated with years of abuse (Bechara et al., 2001; Grant, Contoreggi, \& London, 2000; Rogers et al., 1999), and PFC lesions may render subjects more vulnerable to drug abuse (Bechara et al., 2001). Alternatively, increased levels of impulsivity may predate drug use and thereby predispose individuals to develop an addiction (Cloninger, Svarkic, \& Przybeck, 1993; Scourfield, Stevens, \& Merikangas, 1996). There is currently no resolution to this issue, either in human or animal studies.

\section{Compulsion-impulsivity interactions in addiction}

Despite the distinction between the two behavioural traits of addiction, some researchers suggest that sensitization of the mesolimbic DA neurons produces both compulsion and impulsivity (Goldstein \& Volkow, 2002; Kelley \& Berridge, 2002; Koob \& Le Moal, 2001). It is not that these theories equate the two processes, rather that they employ a very broad definition of compulsion that includes altered decision making and disinhibited responding. This is contrary to clinical definitions of compulsion, which include the following characteristics: (a) recurrent and persistent thoughts, impulses, or images that cause marked anxiety or distress; (b) engaging in an activity that is designed to reduce this anxiety; (c) ritual-like motor movements when engaging in the activity; (d) elicitation of the ritualized behaviour by environmental stimuli; and (e) a recognition that engaging in the activity is excessive or unreasonable (American Psychiatric Association, 1994; Szechtman et al., 2001). The compulsive aspect of drug addiction is manifested as preoccupation with securing and consuming the drug (i.e., craving in humans and drug seeking in animals), but none of these characteristics describes either cognitive or motor impulsivity. Indeed compulsion and impulsivity do not co-occur in most psychiatric conditions, and brain dysfunctions associated with the two disorders are distinct. For example, compulsive disorders (obsessive compulsive disorder, Tourette's syndrome, Huntington's chorea, etc.) are linked to basal ganglia deficits (Pitman, 1989; Rapoport, 1990; Szechtman \& Woody, 2003) whereas impulse control disorders typically involve disruptions in frontal cortical systems (Chow, 2000). Thus, there is no a priori reason to consider that impulsivity and compulsion should overlap in addiction.

In recognition of this distinction, some researchers are beginning to emphasize that impulsivity and compulsion may be two separate 
processes that interact to influence drug use. In one of the first thorough conceptualizations of this relationship, Jentsch and Taylor (1999) describe addiction as the synergism of two distinct phenomenon: enhancement of the rewarding value of drugs and drug-paired stimuli (i.e., compulsion) combined with an inability to withhold responding to these cues (i.e., disinhibition). Importantly, these two processes are mediated by separate neural systems (limbic-amygdala connections and PFC), which are simultaneously altered by chronic drug administration. Goldstein and Volkow (2002) also suggest that alterations in the PFC (specifically orbitofronal cortex and anterior cingulate gyrus) underlie the response inhibition problems in drug addicts. Most recently, Robinson and Berridge (2003) include poor judgement and inappropriate decision making (i.e., cognitive impulsivity) as a consequence of altered PFC function in addicts. These theories are built on the premise that addiction is a progressive disorder (as described previously; Robinson \& Berridge, 1993), in which increasing changes in brain systems alter behaviour in a feedforward manner (Carlezon \& Nestler, 2002; Koob \& Le Moal, 2001). Although the specific details of each theory may vary, they all emphasize that this transition through behavioural stages results in compulsive drug use and loss of control over drug taking, both of which exacerbate the drug-taking cycle.

Even if compulsion and impulsivity interact in drug addiction, investigating these as two separate phenomena will help to isolate the behavioural (and ultimately neural) traits of addiction. For example, addicts may display compulsion and impulsivity simultaneously in that craving is often accompanied by a focus on immediate rewards (cognitive impulsivity) and inappropriate responding (motor impulsivity). In other circumstances, the two processes may compete to control behaviour: Obtaining and securing drugs (drug seeking) often takes considerable planning and execution; rash, spontaneous behaviour (motor impulsivity) as well as an inability to consider future consequences (cognitive impulsivity) would interfere with those activities. In sum, although there is still considerable insight to be gained from studying compulsion in drug addiction, there is now a pressing need to understand how impulsivity contributes to addiction (and vice versa).

\section{A role for animal research}

A major limitation of research examining the relationship between impulsivity and addiction in humans is that these studies are both correlational and retrospective. Thus, it is almost impossible to determine whether any behavioural differences between addicts and controls (i.e., in impulsivity measures) are a cause, or a consequence, of chronic drug use. One recent study (Block, Erwin, \& Ghoneim, 2002) assessed premorbid intellectual function in addicts using historical records of achievement test scores. In this limited sample, addicts exhibited a preexisting deficit in cognitive function, which may have predicted subsequent drug use. In most cases, however, it is difficult or even impossible to objectively measure any pre-addiction function, particularly with behavioural traits such as impulsivity. Therefore, an important next step in this research programme is to experimentally manipulate and control drug experience using animal paradigms. As with many scientific questions, animal research provides the ideal opportunity to establish true causal relationships (in this case between drug administration, impulsivity, and neural changes) because factors such as prior drug experience can be varied systematically.

Animal research provides indirect evidence that drug use contributes to impulsivity in that chronic stimulant administration produces structural (Robinson, Gorny, Mitton, \& Kolb, 2001; Robinson \& Kolb, 1999) and neuropathological (Melega et al., 1996; Ryan, Linder, Martone, \& Groves, 1990) changes in the PFC. In addition, although chronic cocaine does not alter basal levels of cortical 5-HT (Baumann, Raley, Partilla, \& Rothman, 1993; Johnson, Fiorella, \& Rabin, 1993), it does cause regionally specific alterations in 5-HT uptake binding (Belej, Maji, Sioutis, Barros, \& Nobrega, 1996; Burchett \& Bannon, 1997; Cunningham, Paris, \& Goeders, 1992) and 
decreased 5-HT turnover rates in the frontal cortex (Dworkin, Co, \& Smith, 1995). Most importantly, these changes are dose dependent and many persist long after the cessation of drug use. An alternative view is provided by a limited number of animal experiments suggesting that impulsivity predates drug use: In rats, cognitive impulsivity correlates with voluntary ethanol intake (Poulos, Parker, \& Le, 1998), and displays of impulsivity in monkeys predict patterns of ethanol drinking (Higley \& Linnoila, 1997). This work obviously needs to be expanded to include other drugs of abuse and other measures of impulsivity. In that regard, the work of Piazza and colleagues (Piazza \& Le Moal, 1996) on drug-induced sensitization and locomotor responses (presumed to reflect sensation seeking in humans; Nadal, Armario, \& Janak, 2002) provides an excellent model to evaluate the relationship between preexisting differences in impulsivity and vulnerability to self-administer drugs.

If animal research is to provide insight into the relationship between chronic drug use and impulsivity, it should attempt to model, as closely as possibly, the conditions under which humans abuse different drugs. These include drug doses, route of administration, and pattern of intake (e.g., binges). In addition, the effects of active versus passive drug administration should be considered as these can have differential effects on brain function (Di Ciano, Blaha, \& Phillips, 1996; Wilson et al., 1994). This difference probably reflects an effect of the drug on neural systems that mediate learned associations (Everitt et al., 2001; Wise, 2000). The inclusion of a yoked control group provides a relatively simple but powerful control for the effects of active versus passive drug administration. Signalling the infusion in the yoked control group would isolate further the contribution of conditioned cues to behavioural (and neural) changes. Even less appreciated is the fact that learning an operant contingency itself produces brain changes, which undoubtedly interact with drug-induced effects. This highlights a problem in self-administration studies when animals are trained initially to respond for a different reinforcer (e.g., food or another drug). Under these conditions, the effects of various manipulations (including brain lesions or pharmacological challenges) are difficult to assess because altered responses to the previously learned association cannot be distinguished from drug effects. For an excellent discussion of the issues surrounding active versus passive drug administration, including changes in molecular and cellular mechanisms associated with each, see Jacobs, Smit, De Vries, and Schoffelmeer (2003).

In the last few years, animal researchers have undertaken an important investigation of how age of drug exposure alters the propensity to develop an addiction (Andersen, 2003; Laviola, Macri, Morley-Fletcher, \& Adriani, 2003; R. F. Smith, 2003). Virtually all of this work has related age-dependent behavioural (Laviola, Wood, Kuhn, Francis, \& Spear, 1995; Spear \& Brake, 1983) and neural (Adriani et al., 2004; Andersen, 2002) changes to functioning of the mesocortico-limbic DA system. Drug administration during adolescence, however, may have a greater impact on neural circuits associated with impulsivity because these undergo the greatest developmental change from adolescence to adulthood (Paus, 2005). For example, frontal cortical regions mature through adolescence due to increases in myelination and axon diameter (Paus et al., 1999). Metabolic activity declines with development, and the PFC is the last brain region to go through this process (Chugani, Phelps, \& Mazziotta, 1987). During adolescence, the size of the PFC relative to the rest of the brain increases while the density of white matter decreases, a likely reflection of synaptic pruning (Sowell, Thompson, Tessner, \& Toga, 2001). These developmental changes probably explain why inhibitory control improves through adolescence (Williams, Ponesse, Schachar, Logan, \& Tannock, 1999) and why adolescents have a particularly high rate of gambling and impulse control problems (Chambers \& Potenza, 2003). Notably, adolescent rodents also exhibit increased risk taking and sensation seeking (Laviola et al., 2003).

Given these profound developmental changes, brain regions mediating impulsivity may be 
particularly susceptible to drug-induced alterations during adolescence. In support of this idea, adolescent, but not adult, guinea pigs treated chronically with cocaine show increased aggression (which is often associated with impulsivity), due to the drug's effect on serotonergic mechanisms (Deleon, Grimes, Conor, \& Melloni, 2002). Moreover, chronic ethanol intake in adolescent, but not adult, rats disrupts behavioural functions that are mediated by the PFC, both when rats are intoxicated (A. M. White, Ghia, Levin, \& Swartzwelder, 2000) and when they are not (Garcia-Moreno et al., 2002). In humans, adolescents show increased sensitivity to various abused substances (Harrison, Fulkerson, \& Beebe, 2003), which may explain the higher rate of cocaine dependence with lower rates of drug use in this age group (Chen \& Kandel, 2002).

On the other hand, developmental changes that occur prior to adulthood may provide the opportunity to redirect potentially harmful consequences of brain insult (including drug exposure; Andersen, Arvanitogiannis, Pliakas, LeBlanc, \& Carlezon, 2005). Our own work suggests that cocaine exposure during adolescence has fewer detrimental effects in a PFC-mediated task (Paine, McElvie, Dringenberg, \& Olmstead, 2004). In that study, adult cocaine-treated animals displayed deficits in the simple discrimination stage of a set-shifting task (Birrell \& Brown, 2000) that were absent in animals treated during adolescence. Although ceiling effects in adolescent animals may have confounded the findings (i.e., errors to criterion across the task were higher in this group), electrophysiological measures paralleled the behavioural results. That is, the induction of long term potentiation (LTP) in the PFC was reduced in adult, but not adolescent, cocainetreated animals. If synaptic plasticity in the PFC is altered by cocaine treatment only in adulthood, it could indicate that adolescence is a period during which PFC mechanisms are protected, at least partially, against insult. This protection may enhance exploration of novel environments, risk taking, and sensation seeking in adolescents because the impact of long-term consequences and adverse outcomes would be minimized.
From an evolutionary perspective, it would function to promote the development of adult behaviours, including mating outside of the family and community.

The relevance of age-dependent differences in drug responses to the development of addiction is unlikely to be resolved in the near future. For one thing, even in controlled animal experiments, the effect of age on behavioural responses to abused drugs varies with the dependent measure. Compared to adults, adolescent rodents are less sensitive to nicotine's effects in the conditioned taste aversion paradigm (Wilmouth \& Spear, 2004) and more sensitive to the drug's effects in the elevated plus maze (Adriani et al., 2004). Similarly, the effect of stimulants on locomotor sensitization (Collins \& Izenwasser, 2002) and place preference conditioning (Adriani \& Laviola, 2003) are both reduced in adolescence, whereas cross-sensitization to stimulant-induced locomotion is greater in adolescent than in adult rats (Collins \& Izenwasser, 2004). It appears, therefore, that the effect of drugs on various behavioural processes differs with age; the important question is how these interact to alter the susceptibility to drug addiction. Human research into this issue is difficult to interpret because early experimentation with drugs is often associated with other factors that may contribute to addiction, such as conduct disorder, socio-economic status, familial environment, and so on. In contrast, animal research can isolate the contribution of drug exposure and age from these extraneous factors. A resolution to this issue (if there is one) may help to explain why drug use during adolescence is one of the strongest predictors of drug abuse in adulthood (Kandel, Yamaguchi, \& Chen, 1992) and has important ramifications for the "gateway" hypothesis of drug addiction, which is extremely controversial (Morral, McCaffrey, \& Paddock, 2002).

In sum, the causal relationship between drug use and impulsivity can be examined most effectively in animal experiments. Animal studies have already provided detailed knowledge of how neural systems that mediate compulsive drug use are altered with chronic drug administration 
(Carlezon \& Nestler, 2002; Kalivas, Sorg, \& Hooks, 1993; Stewart \& Badiani, 1993), and the relevance of these changes to the rewarding effects of drugs, self-administration, and relapse is becoming apparent (Everitt \& Wolf, 2002; Hyman \& Malenka, 2001). The same model of investigation should be extended to study the impulsive aspects of drug addiction. This research could address how different drugs of abuse alter impulsive behaviours, the parameters (e.g., age of drug administration, pattern of intake, etc.) that are critical for behavioural changes, and the neural mechanisms that mediate these changes. In the end, these investigations may provide information on broader questions beyond the field of addiction, such as how different neural mechanisms control the various components of impulsivity.

\section{Drug-induced impulsivity}

\section{Cognitive impulsivity}

Within the last few years, we initiated a research programme to investigate the relationship between impulsivity and drug addiction. One of the first questions that we addressed was whether drugs induce impulsive responding in rats or humans. Although disinhibited behaviours and risky decision making are often associated with drugged states, controlled laboratory studies have not always confirmed this assumption. For example, neither amphetamine (de Wit, Enggasser, \& Richards, 2002) nor alcohol (Ortner, MacDonald, \& Olmstead, 2003; Richards et al., 1999b) affect cognitive impulsivity in humans, measured as the choice of an immediate small reward over a delayed large reward. Even in rats, the effects of these drugs are not straightforward: Amphetamine increases impulsivity in the Delayed Reinforcement task (Evenden \& Ryan, 1996), whereas both amphetamine and methamphetamine decrease impulsivity in the Adjusting Amounts procedure (Richards, Sabol, \& de Wit, 1999a; Wade, de Wit, \& Richards, 2000). Both tasks measure the ability to delay gratification, but the Adjusting Amounts procedure systematically varies the amount of the immediate small reward to determine the quantity of this alternative, which equates to the large delayed reward at each interval. In contrast, the Delayed Reinforcement paradigm assesses the preference for set amounts of small and large rewards when the delay to the latter is varied. Thus, one paradigm provides a measure of how much the immediate reward is valued, and the other which of two alternatives is preferred. This methodological difference could account for the conflicting effects of amphetamine in the two paradigms, but it is more likely that the presence (Adjusting Amounts) versus the absence (Delayed Reinforcement) of a cue signalling the delay to the large reward explains the discrepancy: Amphetamine decreases choice of a large delayed reward when no cue is present and increases the choice when a cue is present (Cardinal, Robbins, \& Everitt, 2000).

Despite the pharmacological similarities between amphetamine and cocaine, we have never observed an effect of cocaine on cognitive impulsivity in rats (Paine \& Olmstead, unpublished observation), even though we used three different Delayed Reinforcement paradigms and tested animals with and without a cued delay. Thus, there may be a dissociation between the effects of psychostimulants on this measure. In addition, alcohol increases the choice of a small immediate reward over a large delayed reward in both free-operant (Hellemans, Nobrega, \& Olmstead, 2005) and discrete-trials (Poulos et al., 1998) versions of the Delayed Reinforcement task, although the effect is not observed in human studies. The differential effect of these three drugs on the ability to delay gratification in rats (amphetamine increases or decreases depending on the cue, alcohol increases, and cocaine does not change) is further evidence that cognitive impulsivity is mediated by specific pharmacological mechanisms.

The apparent contradiction between laboratory results and real-life situations, and between human and rat studies of cognitive impulsivity, raises the possibility that drug-induced changes in behaviour are due to an effect on other processes. One suggestion is that drugs, such as alcohol, alter 
decision making because intoxicated individuals focus almost exclusively on the most salient cues in their environment (Steele \& Josephs, 1990). According to this "alcohol myopia" theory, alcohol produces impulsive behaviour in real-life situations (e.g., drunk driving, aggression, unprotected sex) because the cues that signal immediate short-term rewards (e.g., sexual gratification) are generally more salient than the possible negative, long-term consequences (e.g., contracting AIDS). If this is true, behaviour under the influence of alcohol should be controlled by salient cues, regardless of whether they impel or inhibit responding. In support of this idea, intoxicated individuals report less intention to engage in risky behaviour if the strength of the cues inhibiting their behaviour is increased (MacDonald, Fong, Zanna, \& Martineau, 2000; MacDonald, Zanna, \& Fong, 1996). Based on these findings, we suggested that cognitive impulsivity is reduced in intoxicated individuals tested in the laboratory (Ortner et al., 2003) because the laboratory setting (e.g., presence of the experimenter, knowledge that the experimenter would later view the data, etc.) may have provided salient inhibiting cues. This would fit with the evidence that ethanol produces positive subjective effects when consumed in a social situation and aversive affects when consumed in isolation (Doty \& de Wit, 1995).

In order to further examine the phenomenon of alcohol myopia, we developed a rat model of myopia using a modified version of the delayed reinforcement t-maze task (Olmstead, Hellemans, \& Paine, in press). In this paradigm, a light in one arm predicts either a small immediate (2 sucrose pellets) or a large delayed (12 sucrose pellets after $10 \mathrm{~s}$ ) reward, but the arm paired with the light varies across trials. Alcohol dose-dependently increased the choice of the lit arm, regardless of whether it signalled the small or the large reward. This indicates that rats, like humans, are influenced by cue salience when intoxicated. The fact that alcohol did not alter impulsivity (i.e., it did not increase the choice of the immediate reward) in this paradigm suggests that myopia, not impulsivity, was controlling behaviour under the influence of the drug. We are now testing whether other drugs induce myopic responding in order to determine whether altered decision making under the influence of psychoactive substances may be explained in terms of a general theoretical framework. If so, it may explain why amphetamine decreases cognitive impulsivity in humans who are tested in a laboratory (de Wit et al., 2002).

The suggestion that intoxicated individuals are myopic is consistent with evidence that alcohol induces cognitive impairments (Brooks, Hennebry, McAlpin, Norman, \& Little, 2002; Hoaken, Assaad, \& Phil, 1998; Rossetti et al., 2002). That is, alcohol myopia theory states that alcohol restricts cognitive processes such that intoxicated individuals are unable to simultaneously process multiple pieces of information (i.e., they display cognitive short-sightedness). At the same time, it is unlikely that alcohol caused severe amnesia or general confusion in our myopia paradigm because the choice of the lit arm under the influence of alcohol was greater than $50 \%$ (i.e., random responding). Whether reports of cognitive deficits in other paradigms can be explained by alcohol myopia remains an open question.

The concept of alcohol (or drug-induced) myopia also fits with descriptions of behavioural stereotypy that occurs following administration of stimulants (Creese \& Iversen, 1974; Randrup \& Scheel-Kruger, 1966) or alcohol (Devenport \& Merriman, 1983). Drug-induced stereotypy and locomotion are mediated through distinct pharmacological mechanisms (Sahakian, Robbins, Morgan, \& Iversen, 1975), and the two behaviours may compete with one another. That is, with increasing drug doses, forward locomotion decreases as behaviour directed toward specific stimuli increases (Blanchard et al., 1998). Thus, both myopia and stereotypy describe the drugged state as a narrowing of behavioural repertoire produced by a focus on salient environmental cues. This fits with the suggestion that tasks whose mastery entails repetition, few topographies, and a rigid structure will improve with alcohol administration, whereas those requiring 
change and the sampling of new strategies will be impaired (Devenport \& Merriman, 1983). One fascinating observation is that rats displaying stereotypy during cocaine binge sessions can disengage from the stereotypic response to lever press for the drug (Paine, Krendler, \& Olmstead, unpublished observation). Stereotypy, therefore, is not simply a "locking in" of a behavioural response but may reflect the concept of probability dependency in which the effect of the drug depends, in part, upon the baseline probability of a response (Hobbs, Rall, \& Verdoorn, 1996; Schwartz \& Marchok, 1974).

The idea that drugs increase the control of behaviour by salient environmental cues is reminiscent of the gain theory of mesolimbic DA (Cohen \& Servan-Schreiber, 1992). Like alcohol myopia theory, this position explains druginduced behavioural changes as altered responses to salient cues, although neither theory specifies whether a cue becomes more salient or whether the behaviour evoked by a cue is magnified in a drugged state. The fact that increases in DA are associated with compulsion in drug addiction raises an important issue of how to distinguish the effects of drugs on impulsivity and compulsion. That is, if cognitive impulsivity reflects myopia, myopia is equated with DA gain, and DA gain is responsible for compulsion, are the two behavioural traits of addiction separable? Again, the obvious way to approach this issue is through controlled animal experiments. For example, if alcohol-induced impulsivity is really myopia, the two should be mediated by similar neuropharmacological mechanisms. Surprisingly, there is little understanding of the mechanisms underlying alcohol-induced impulsivity, despite the link between 5-HT and impulsivity and the evidence that alcohol affects serotonergic transmission (Hobbs et al., 1996; Lovinger, 1999). Our work suggests that the increased choice of a small immediate reward (i.e., cognitive impulsivity) following ethanol administration is reduced by the 5-HT agonist, p-chloroamphetamine (Olmstead et al., in press). The same manipulation had minimal effects in the myopia paradigm suggesting that alcohol-induced myopia and impulsivity may be distinct processes. If these results are confirmed, we may conclude that myopia and impulsivity are each manifested under specific environmental conditions, in this case the task requirements of the two paradigms. We also examined the relationship between myopia and DA by testing whether manipulations of the mesolimbic DA system alter responding in the myopia paradigm. These studies should shed light on what myopia reflects, how it is related to cognitive impulsivity, and whether the two processes are distinct, overlapping or mediated by some third, unknown, factor.

\section{Motor impulsivity}

Like cognitive impulsivity, the effect of drugs on motor impulsivity is controversial, at least when it is measured in the laboratory. For example, in both rats and humans, alcohol increases (de Wit, Crean, \& Richards, 2000; Feola, de Wit, \& Richards, 2000) or does not affect (Hellemans et al., 2005; Ortner et al., 2003) motor impulsivity, and psychostimulants are associated with increases (Cole \& Robbins, 1987; Fillmore \& Van Selst, 2002; Ridley, Baker, \& Weight, 1980) and decreases (de Wit et al., 2000; de Wit et al., 2002; Feola et al., 2000) in this measure. Individual differences may explain some of these discrepancies in that the effect of drugs on motor impulsivity depends on preexisting traits such as reaction time (de Wit et al., 2000), baseline inhibitory control (Feola et al., 2000), and working memory capacity (Finn, Justus, Mazas, \& Steinmetz, 1999). More importantly, because drugs act on multiple neural systems, behavioural measures of disinhibtion may be confounded by disruptions in other motor or cognitive abilities.

In our own study, therefore, we examined the effect of cocaine on motor impulsivity in rats and tested whether any observed deficit was due to changes in other processes (Paine \& Olmstead, 2003). We used an asymmetrically reinforced go/no-go task in which disinhibition is reflected as a selective increase in responding during no-go intervals (Fletcher, 1993). Because accurate performance in this task depends on the ability to use conditional rules (i.e., lever press in one

\section{THE QUARTERLY JOURNAL OF EXPERIMENTAL PSYCHOLOGY, 2006, 59 (4)}


stimulus condition but not the other) and to detect and respond to visual stimuli, we also tested the effect of cocaine in conditional discrimination and vigilance tasks. In the conditional discrimination task, rats learn the rule "in the presence of one stimulus press the right lever, in the presence of another stimulus press the left lever" (Chudasama, Bussey, \& Muir, 2001). In order to obtain an independent measure of disinhibition, we measured responding during a 1-s delay prior to the stimulus onset. Cocaine disrupted conditional discrimination and increased premature responding, consistent with evidence that psychomotor stimulants increase premature responding in the 5-choice serial reaction time task (Cole \& Robbins, 1987), and decrease interresponse times on differential-reinforcement-of-low-rates schedules (McClure \& McMillan, 1997; Sabol, Richards, Layton, \& Seiden, 1995; Wenger \& Wright, 1990; Woolverton, Kandel, \& Schuster, 1978). The deficit in conditional discrimination was not eliminated by increasing the stimulus duration, suggesting that cocaine does not alter attentional processes. This was confirmed in a vigilance task (Chudasama \& Muir, 2001) which assesses the ability to detect and respond to a brief stimulus presented randomly throughout a session. In sum, we concluded that cocaine increases behavioural disinhibition and that this increase may be independent of an impairment in conditional discrimination.

Our finding that cocaine produces behavioural disinhibition is consistent with some reports (Cole \& Robbins, 1987; Fillmore et al., 2002; Ridley et al., 1980), but contradicts others (de Wit et al., 2000; de Wit et al., 2002; Feola et al., 2000). Task differences may explain some of these inconsistencies in that, in the stop task (Feola et al., 2000), animals must stop a response in progress in order to make an alternative response whereas, in the go/no-go task (our study), animals must refrain from making responses during no-go intervals. Given that amphetamine improves stop-task performance (Feola et al., 2000), and cocaine impairs go/nogo performance (Paine \& Olmstead, 2003), psychostimulants may improve the ability to switch responses, but impair the ability to withhold responding. Alternatively, these discrepancies may be explained by the consequences of inappropriate responding: In the stop task, reward is withheld when stop failures occur, whereas responding during no-go intervals has no programmed consequences. This may produce motivational differences associated with inhibited responding in the two tasks, which could interact with drug effects. That said, cocaine increased premature responses in the conditional discrimination task, thereby terminating the trial without the ability to attain reward. Thus, the motivation for inhibited responding should be similar in our experiment and in the stop task. It is more likely, therefore, that differences in response requirements explain the disparate effects of psychostimulants on behavioural disinhibition. Finally, we cannot rule out the possibility that cocaine and amphetamine have different effects on motor impulsivity, or that either drug would produce different effects in a symmetrically reinforced go/ no-go task (i.e., animals are reinforced for not responding during no-go intervals).

All of the studies noted above (including our own) examined the effects of drugs on motor impulsivity when animals were responding for natural rewards (food or water). Although this design allows the experimenter to control drug doses and exposure, inhibitory mechanisms may be mediated by different processes when subjects are responding for drug. The fact that blood alcohol levels correlate with the self-reported desire to consume more alcohol (Ortner et al., 2003) suggests that the ability to limit drug intake may be reduced in intoxicated states. Certainly, unlimited access to stimulants produces periods of disinhibited and uncontrolled drug intake in both humans (Gawin \& Ellinwood, 1988) and rats (Bozarth \& Wise, 1985). During these binge sessions, regular patterns of responding break down, and activities not directed towards the drug (e.g., grooming, sleeping, eating and drinking) are reduced. As the binge progresses, interinfusion intervals become increasingly erratic, although rats still maintain a constant hourly intake of cocaine when the dose is varied 
(Tornatzky \& Miczek, 1999). This suggests that short- but not long-term regulatory mechanisms break down during the binge. Changes in response rates, therefore, cannot be explained by a change in reinforcing efficacy, but may reflect changes in inhibitory processes. If so, behavioural changes across binge sessions should correlate with changes in neural systems associated with impulsivity. Moreover, if these neural changes are long lasting, rats that have undergone binge sessions should exhibit increased impulsivity, even in the absence of the drug. Although we do not have answers to these specific question, related issues are currently being addressed (see recent work of K. A. Miczek, A. G. Phillips, D. C. S. Roberts and their colleagues), which should yield some important information.

One of the biggest obstacles to understanding the mechanisms underlying bingeing is that there is no consensus on what constitutes a drug binge. This is particularly true in the human literature, which generally employs a loose criterion of a minimum amount of drug consumed per occasion (often with no time specified for the occasion). Because there is no consideration of individual differences in regulated intake (i.e., during nonbinge periods) or of changes in rate of intake across the occasion, there is no way to determine whether these binges represent periods of disinhibited drug intake. Even in rat studies, we have no operational definition of the breakdown in regulatory control that is assumed to occur during drug binges. Tornatzky and Miczek (2000) have provided the best characterization of behavioural changes during binges by calculating changes in interinfusion intervals across time. This analysis of root mean square of successive differences provides a statistically reliable measure of variability over a specified time period. Nonetheless, in order to determine the point of transition from regular to irregular drug intake, we require an algorithm that characterizes the regular intake pattern for individual rats during limited access sessions and in the initial phase of unlimited access sessions. These data (including means, variability, and successive differences of interinfusion intervals) would then be used as a template during the binge sessions to determine deviations from regularity (i.e., breakdown in behavioural control). For example, irregular intake could be defined as a period during which the standard deviation of the root mean squared of successive differences lies outside the standard deviation range of the regular intake patterns, but the standard deviation of the interinfusion interval is not significantly altered. That is, the variability in intake patterns is significantly increased, without changing the overall level of intake. This formula would distinguish irregular intake from abstinence periods, which also occur throughout the binge sessions. Obviously, a critical issue is time resolution and the need to validate any algorithm by applying it to a large sample of binge sessions.

Once the criteria for regular and irregular intake are established, the behavioural patterns associated with each period need to be mapped to neurochemical changes. We have some knowledge of the changes that occur during "binge" sessions in which the drug is administered by the experimenter (Kuczenski \& Segal, 1997; Lindholm, Rosin, Dahlin, Georgieva, \& Frank, 2001; Maisonneuve \& Kreek, 1994; Segal \& Kuczenski, 1999; Zhang, Schlussman, Ho, \& Kreek, 2001), but all of these studies focus on dopaminergic mechanisms in the striatum. If irregular or binge patterns of intake represent a breakdown in impulse control, they are more likely to be reflected by changes in 5 -HT mechanisms in the $\mathrm{PFC}$, although there is also evidence for cortical DA dysfunction in these conditions (Dalley, Theobald, Eagle, Passetti, \& Robbins, 2002a). Experiments combining self-administration and microdialysis techniques are obviously laborious, but certainly not without precedent. And they could address critical questions concerning druginduced impulsivity such as what are the neurochemical correlates of bingeing, do these change with repeated binge sessions, how do they interact with brain reward systems, and why do some drugs of abuse not instil binge patterns of intake. Understanding the effect of drugs on motor impulsivity is an important issue because the loss of inhibitory control under the influence of drugs 
could lead to further drug taking and ultimately contribute to the cycle of addiction.

\section{Chronic drug exposure}

In addition to our investigations of drug-induced effects, we are investigating the impact of chronic drug exposure on impulsivity. First, we tested whether chronic cocaine administration alters cognitive or motor impulsivity in rats, using the delayed reinforcement and go/no-go tasks, respectively. Although our treatment regime $(20 \mathrm{mg} / \mathrm{kg}$, three times per day for 14 days) increased behavioural sensitization scores (Kilbey \& Ellinwood, 1977), it only produced a transient increase in cognitive impulsivity that recovered across testing (Paine, Dringenberg, \& Olmstead, 2003). These data contradict previous evidence that chronic methamphetamine reduces indifference points in an Adjusting Amounts procedure (Richards et al., 1999a), although impulsivity scores across days are not presented in the Richards et al. paper making direct comparisons between the two experiments difficult. Nonetheless, dosing regimes and time of testing were similar, so the discrepancy may be related to differences in behavioural procedures in the two studies. More specifically, the Adjusting Amounts procedure systematically varies the magnitude of the immediate reward; indifference points are calculated as the reward quantity that equates the immediate and delayed rewards. In contrast, indifference points in the Delayed Reinforcement paradigm reflect the delay to the large reward that equates the two alternatives. Furthermore, the delay to the large reward is signalled by a cue (light) in the Adjusting Amounts procedure, which can influence the choice of the small or large reward (Cardinal et al., 2000). Whether these procedural differences explain the contradictory effects of chronic stimulant administration on cognitive impulsivity remains an open question.

We also found that chronic cocaine had no effect on motor impulsivity (Paine et al., 2003), despite evidence that chronic methamphetamine increases perseverative errors in a reversal-learning paradigm in monkeys (Jentsch, Olausson, De La Garza, \& Taylor, 2002). To the extent that impaired inhibition of a previously learned response and the inability to withhold responding in the presence of a discriminative stimulus reflect similar processes, the two studies produced contradictory results. Indeed we were surprised at the minimal behavioural effects that we observed, particularly as similar dosing regimes can produce pronounced neural and behavioural changes (Burchett \& Bannon, 1997; Unterwald, Ho, Rubenfield, \& Kreek, 1994;). Moreover, cortical serotonergic mechanisms were partially compromised in our study in that the 5-HT receptor antagonist, methiothepin, was more effective in blocking electrocorticogram (ECoG) activity in cocaine- than in saline-treated animals.

A possible explanation for the discrepancy between our study and both the Richards et al. (1999a) and Jentsch and Taylor (2003) studies is the chronically administered drug: cocaine versus methamphetamine. Both stimulants produce their rewarding effects by blocking DA transporter mechanisms in the nucleus accumbens (Wise, 1996) and induce similar behavioural profiles when administered in binge patterns (Segal \& Kuczenski, 1997a, 1997b). Nonetheless, repeated administration of methamphatemine and cocaine have different effects on striatal DA and 5-HT transporter function in vivo (Fleckstein et al., 1999), and prolonged exposure to cocaine does not produce the same level of neurotoxic effects on striatal DA or 5-HT systems as that observed with chronic methamphetamine administration (Kleven, Woolverton, \& Seiden, 1988).

This raises an important question of how long-term administration of different drugs may influence behavioural processes. If impulsivity is a consequence and not a cause of addiction, drugs that produce the most dramatic effect on PFC or 5-HT systems should be associated with higher levels of impulsivity. In that respect, the street drug 3,4-methylenedioxymethamphetamine (MDMA or Ecstasy) is an obvious candidate: it preferentially targets the 5-HT transporter system, increasing synaptic levels of 5-HT following acute administration (Rudnick \& Wall, 1992). 
In contrast, chronic MDMA administration induces selective 5-HT loss in both rats and nonhuman primates, particularly in forebrain and cortical regions (Morgan, 2000). MDMA use in humans is associated with reduced CSF levels of 5-HT and its metabolites (McCann, Ridenour, Shaham, \& Ricaurte, 1997), upregulation of 5-HT receptors (Reneman, Booij, Schmand, Van den Brink, \& Gunning, 2000), and reduced neuronal activity in the PFC (Reneman, Majoie, Schmand, Van den Brink, \& den Heeten, 2001). Given these changes, it is not surprising that MDMA users display high-risk behaviours (Klitzman, Pope, \& Hudson, 2000) and increased impulsivity (Morgan, 1998). At the same time, Kish (2002) argues that the evidence for 5-HT dysfunction in MDMA users is equivocal, partly because self-reports of prior drug use are unreliable. Again, this is an obvious place for animal research to address a controversial question. At least one study suggests that chronic MDMA administration increases motor impulsivity in rats, reflected as an inability to withhold inappropriate responses in an appetitive conditioning paradigm (Taylor \& Jentsch, 2001). Importantly, neither cocaine nor amphetamine treatment produced similar effects. These data support the hypothesis that the behavioural effects of longterm drug use are determined by alterations in specific neural systems and that these vary with drug class. In line with this idea, the nature of cognitive deficit in drug addicts depends, at least in part, on the addicts' drug of choice (Ornstein et al., 2000; Rogers et al., 1999). This hypothesis may also explain the distinct patterns of drug use associated with different drug classes. That is, only some drugs (e.g., cocaine, amphetamine, and alcohol) produce binge-like patterns of drug intake, and MDMA and hallucinogens do not produce compulsive drug seeking that is characteristic of cocaine, alcohol, nicotine, and, to some extent, opiates.

\section{The study of individual differences}

Even if chronic drug administration produces neural changes that increase the propensity to abuse drugs, preexisting individual differences undoubtedly contribute to differential rates of addiction. In support of this idea, drug addiction is associated with specific personality traits (Cloninger et al., 1993; Scourfield et al., 1996), and, in rats, the propensity to self-administer drugs can be predicted by locomotor responses to novelty and glucocorticoid responses to stress (Piazza \& Le Moal, 1996). The latter effect is due to enhanced activity of the mesolimbic DA system, which increases the reinforcing efficacy of abused drugs. This mechanism, therefore, could underlie compulsive drug seeking, but it is unlikely that it mediates either cognitive or motor impulsivity associated with addiction. Thus, although it seems intuitive, there is little or no empirical evidence that trait differences in impulsivity predict patterns of drug intake. Nor do we understand how these preexisting differences may interact with drug experience. Again, these questions could be examined most effectively in animal paradigms because factors such as prior drug experience can be varied systematically. Indeed, the work of Piazza and colleagues on drug-induced sensitization and locomotor responses (presumed to reflect sensation seeking in humans; Nadal et al., 2002) provides an excellent model to evaluate the relationship between individual differences in impulsivity and vulnerability to self-administer drugs. To date, there is limited evidence on this question: In rats, cognitive impulsivity correlates with voluntary ethanol intake (Poulos et al., 1998), and displays of impulsivity in monkeys predict patterns of ethanol drinking (Higley \& Linnoila, 1997). This work obviously needs to be expanded to include other drugs of abuse and other measures of impulsivity.

Individual differences in impulsivity are determined partially by genetics (Brunner \& Hen, 1997), although nongenetic factors also play a major role in most complex behavioural traits (Crabbe, Phillips, Buck, Cunningham, \& Belknap, 1999). One important factor may be early life experience in that childhood abuse increases the incidence of both addiction (Harrison, Fulkerson, \& Beebe, 1997) and impulsivity (Brodsky et al., 2001). Moreover, early 
parental neglect in monkeys is associated with decreased 5-HT levels, increased impulsivity, and excessive alcohol intake (Higley \& Linnoila, 1997). Neurobiological data provide indirect evidence for a link between adverse early experience and impulsivity: Rearing rats in social isolation reduces 5-HT neurotransmission, metabolite levels, and turnover in the PFC (Hall, 1998); isolation rearing in gerbils reduces DA input to the orbitofrontal cortex (Neddens, Lesting, Dawirs, \& Teuchert-Noodt, 2002); and PFC lesions and isolation rearing induce the same selective attentional deficit in rats (Schrijver \&Wurbel, 2001). The effect of isolation rearing interacts with genetic factors in that monkeys with adverse early experiences are differentiated by genotype in cerebrospinal fluid concentrations of the 5-HT metabolite 5-hydroxyindoleacetic acid, whereas monkeys reared normally are not (Bennett et al., 2002).

Given the behavioural and neural profiles of animals reared in social isolation, we predicted that this adverse early experience would alter impulsivity in adult rats. On the contrary, our data show that isolation rearing does not affect on motor impulsivity and only affects cognitive impulsivity when rats are intoxicated (Hellemans et al., 2005). Although contrary to our hypothesis, these data are consistent with evidence that isolation rearing enhances behavioural responses to ethanol (Hall, Huang, Fong, Pert, \& Linnoila, 1998a) and does not effect impulsivity in an attentional task, except under the influence of amphetamine (Dalley, Theobald, Pereira, Li, \& Robbins, 2002b). These findings led us to conclude that the relationship between adverse early experience and impulsivity is mediated by an intervening variable such as stress, which may be induced by drug administration.

If isolation rearing alters some behavioural process (such as impulsivity), which then interacts with drug experience, it may explain why research examining the effect of isolation rearing on drug self-administration is so controversial. Isolation rearing has been reported to increase (Alexander, Coambs, \& Hadaway, 1978; Boyle, Gill, Smith, \& Amit, 1991; Deatherage, 1972;
Schenk, Lacelle, Forman, \& Amit, 1987; Schenk, Gorman, \& Amit, 1990; Schenk, Robinson, \& Amit, 1988), decrease (Hill \& Powell, 1976; Phillips, Howes, Whitelaw, Robbins, \& Everitt, 1994a; Phillips et al., 1994b), or not change (Bozarth, Murray, \& Wise, 1989; Kazmaier, Butcher, Senter, \& Stutz, 1973; Rockman, Hall, Markert, \& Glavin, 1988) drug intake. Some of these discrepancies may be explained by shifts in the dose-response curve with isolation rearing (Howes, Dalley, Morrison, Robbins, \& Everitt, 2000) or by strain differences, which interact with the effects of isolation rearing on responses to drugs (Hall, Huang, Fong, Pert, \& Linnoila, 1998b). At the same time, given the multitude of neurochemical and behavioural changes in isolation-reared rats (Robbins, Jones, \& Wilkinson, 1996), it is likely that adverse early experience alters the propensity to abuse drugs through a variety of mechanisms. These may include changes in the likelihood that an individual will experiment with drugs, experience anxiolytic effects with early drug use, continue drug use despite adverse consequences, develop compulsive behaviours, exhibit disinhibited drug intake, self-medicate withdrawal symptoms, and so on. These processes may be dissociable in that high levels of depression, anxiety, and stress all predict drug self-administration (Homberg et al., 2002; Markou, 1998), but the three conditions are associated with distinct neurochemical profiles.

Recently, an emphasis has been placed on prenatal drug exposure as a predictor of adult differences in addiction rates (Baer, Sampson, Barr, Connor, \& Streissguth, 2003; Buka, Shenessa, \& Niaura, 2003; Hellstrom-Lindahl \& Noberg, 2002; Mattson, Schoenfeld, \& Riley, 2001). In utero exposure to cocaine, heroin, $\mathrm{TCH}$, nicotine, or alcohol produces cognitive and motor deficits in both humans and animals (Baglenova, Birru, Pandiella, \& Breese, 2004; Gendle et al., 2003; Harvey, 2004; Iqbal, Dringenberg, Brien, \& Reynolds, 2004; Mattson et al., 2001; Singer et al., 2004; A. M. Smith, Fried, Hogan, \& Cameron, 2004) that are associated with alterations in brain reward systems 
(Chen, Maier, \& West, 1997; Choong \& Shen, 2004; Glatt, Trksak, Cohen, Simeone, \& Jackson, 2004; Kane, Fu, Matta, \& Sharp, 2004; Salvatore et al., 2004; Shen, Hannigan, \& Kapatos, 1999). Despite these findings, the effects of prenatal drug exposure on subsequent drug self-administration in animals is inconclusive (Keller, LeFevre, Raucci, \& Carlson, 1996; Ramsey, Niesink, \& Van Ree, 1993; Rocha, Mead, \& Kosofsky, 2002). As in the social isolation model, in utero drug exposure probably induces numerous behavioural effects that may alter the propensity to self-administer drugs. The evidence for increased impulsivity in humans following prenatal drug exposure is compelling, both for alcohol (Kodituwakku, May, Clericuuzio, \& Weers, 2001; Mattson \& Riley, 1998; Nanson \& Hiscock, 1990; Streissguth, Martin, Barr, \& MacGregorSandman, 1984) and for tetrahydrocannabinol (THC) (A. M. Smith et al., 2004), although isolating one behavioural effect in humans with multiple problems (e.g., foetal alcohol syndrome) is difficult, if not impossible.

Our own work investigated the relationship between in utero alcohol exposure and behavioural effects, using a guinea pig model of chronic prenatal ethanol exposure (CPEE; Abdollah, Caitlin, \& Brien, 1993). The guinea pig is the most parsimonious model to examine prenatal ethanol exposure because its extensive prenatal brain development parallels that of humans. In particular, the brain growth spurt is a perinatal event in humans and guinea pigs, but a postnatal event in the rat and mouse (Dobbings \& Sands, 1979). In addition, the guinea pig has a placenta that is most similar to human placenta among small animal species, and it has a trimester-equivalent gestation that is similar to that of the human (Martensson, 1984). In our study, CPEE induced a pronounced behavioural deficit in a lever-pressing task, manifested as a high magnitude of responding during extinction trials (Hayward et al., 2004). This result is remarkably consistent across multiple paradigms that measure response inhibition in animals (Abel, 1982; Driscoll, Streissguth, \& Riley, 1990; Riley, Lochry, \& Shapiro, 1979; Riley, Shapiro, Lochry, \& Broida, 1980). In subsequent work, we confirmed that CPEE guinea pigs exhibit higher levels of motor impulsivity in a go/no-go task, with no perseverative deficit in a reversal learning task (Martin \& Olmstead, unpublished observation). CPEE-treated animals also exhibit alterations in gamma-aminobutyric acid (GABA) and glutamatergic mechanisms in the hippocampus (Richardson, Byrnes, Brien, Reynolds, \& Dringenberg, 2002), although the behavioural changes in response inhibition are more likely due to deficits in PFC mechanisms.

Thus, there are many factors that may mediate the relationship between individual differences and drug addiction. To date, animal research has focused on describing the relationship between sensation seeking (i.e., sensitized locomotor responses) and drug self-administration, but future studies should focus on understanding the contribution of other factors, including impulsivity. In that respect, the role of both genetic and environmental factors should be examined, as well as how these variables interact with chronic drug use. Finally, although the studies are more problematic, animal research could also investigate whether individual differences (produced by both genetic and environmental variables) predict differential responses to various classes of abused drugs.

\section{CONCLUSIONS}

Understanding the relationship between impulsivity and addiction is related to the more general question of how drug administration (both acute and chronic) affects cognitive processes. First, cognitive impulsivity is measured as an increased choice of small immediate over large delayed rewards, but this effect may be produced by deficits in attention, an inability to discriminate reward magnitude, disruptions in time perception, a misunderstanding of response contingencies, an inability to consider future events, a distortion in the value of long-term consequences, and so on. Similarly, apparent deficits in motor impulsivity may be produced by disruptions in sensory, motor, or timing abilities, even if the ability to withhold a prepotent response is intact. 
To further complicate the issue, some cognitive deficits may be explained by changes in impulsivity because tests of cognitive function (i.e., discrimination) can be disguised as impulsivity tasks (e.g., go/no-go). Again, an advantage of animal research is that it provides dissociable measures of individual processes and can rule out alternative hypotheses with the proper control conditions. As an example, gonadal hormones have distinct effects on impulse control and divided attention in rats (Jentsch \& Taylor, 2003), and separate neurochemical systems mediate attention and response control in the 5-choice serial reaction time task (Ruotsalainen, Miettinen, MacDonald, Koivisto, \& Sirvio, 2000).

Even if the components of cognition and impulsivity can be dissociated in the laboratory, it is likely that the two processes interact. For example, working memory and conditioned associative learning can modulate disinhibition (Finn et al., 1999), and cognitive deficits are associated with increased impulsivity (Lau, Pihl, \& Peterson, 1995). This interaction may be an important factor in addiction as drug-induced impulsivity could reflect a lowered threshold for the cognitive modulation of impulsivity (Finn et al., 1999; Lau et al., 1995). Even so, of the few theories that emphasize cognitive factors in addiction (Everitt et al., 1999; Tiffany, 1990; N. M. White, 1996; Wise, 1999), none explicitly discuss impulsivity.

In some cases, the relationship between the two is implicit. For example, according to Tiffany (1990), drug action schema (i.e., drug-taking behaviours) are automatic processes elicited by environmental stimuli. These may be blocked by voluntary cognitive processes that promote abstinence. The two cognitive processes (automatic and nonautomatic) compete with one another and with other cognitive processes, such as those activated by negative affect (e.g., withdrawal). Ultimately, this increase in effortful cognitive processing leads to relapse by breaking down the inhibition of prepotent or automatic drug-taking responses.

In contrast, Wise (1999) explains drug selfadministration in rodents as the product of immediate and historical antecedents, rather than knowledge about the consequences of the action. In other words, drug taking is controlled by learned expectancies of local stimulus-reward associations and not the consideration of longterm events. This essentially describes cognitive impulsivity (i.e., the choice of immediate over delayed rewards), although Wise would disagree that the contingencies associated with each choice are "understood". He does point out that cognitive factors may have a greater impact on addiction-related impulsivity in humans than in rats. In particular, drug taking is inhibited in rats during withdrawal, whereas culturally transmitted beliefs, insights into physiological states, and so on may disinhibit this behaviour in humans.

Finally, several theories emphasize that drugs of abuse interact with forebrain systems that mediate different cognitive processes (Everitt et al., 1999; Wise, 1999). Because these systems influence working memory, decision making, and control of behaviour by conditioned cues, they may ultimately impact, either directly or indirectly, on impulsivity. One goal of animal research should be to identify if and when altered decision making, under the influence of drugs, can be explained by impulsivity, as well as whether drugs can influence cognitive processes without affecting impulsivity. Understanding the role of cognitive factors in addiction (and how these interact with other factors such as impulsivity) is important because addicts display cognitive deficits (Bolla, Funderburk, \& Cadet, 2000) that may seriously impair treatment options (Bates, Bowden, \& Barry, 2002; Bowden, Crews, Bates, Fals-Stewart, \& Ambrose, 2001).

While still focusing on compulsion, therefore, future research should place increasing emphasis on the role of impulsivity in the establishment and maintenance of drug addiction. This review focuses on motor and cognitive impulsivity as being particularly important to addiction and emphasizes that the two processes are dissociable. The suggestion that the primary features of cognitive and motor impulsivity can be identified and measured independently is consistent with the idea that impulsivity is not a unitary construct (Barratt \& Patton, 1983). Moreover, the fact that 
behavioural measures of the two processes do not always correlate supports evidence that subcomponents of impulsivity are mediated by distinct (although possibly overlapping) neuropharmacological substrates (Evenden, 1999). Some theories conceptualize the different subcomponents of impulsivity within a single framework (Gerbing, Ahadi, \& Patton, 1987), but this position does not presume that the subcomponents can not act independently. In addition, analyses of drug-taking behaviour using economics models (Bickel \& Marsch, 2001) may provide insight into the factors that influence impulsivity in drug addicts.

A critical issue in addiction research is how compulsion and impulsivity interact: Do the two traits develop independently or simultaneously, or does the development of one maladaptive behaviour (e.g., compulsion) lead to the other (e.g., impulsivity)? These questions are particularly difficult to address because drugs of abuse interact with numerous neural substrates, and no brain system can be considered in isolation. Any post hoc or correlational analysis of brain-behaviour relationships, therefore, will provide an incomplete account of addiction. The most effective way to understand maladaptive drug use is to combine these studies with carefully controlled animal experiments that allow the dissociation of neural systems and the isolation of behavioural processes. In the end, determining the relative contribution of compulsion and impulsivity to addiction will provide an important piece in the puzzle of this disorder.

In conclusion, the most comprehensive description of drug addiction will incorporate mechanisms of both impulsivity and compulsion. Currently, our understanding of compulsion (both neural and behavioural processes) far outweighs that of impulsivity, even though impulsivity is a significant predictor of level of abuse and of treatment retention (Moeller et al., 2002). Nonetheless, as emphasized many times in the past, the development of drug addiction is affected by social, cultural, and developmental factors, which ultimately impact on biological and psychological processes. Even though impulsivity is only one component, understanding how it impinges on drug addiction will improve our ability to treat this debilitating disorder. There is no doubt that animal research can contribute to this knowledge.

Original manuscript received 7 April 2005 Accepted revision received 10 September 2005 PrEview proof published online 30 January 2006

\section{REFERENCES}

Abdollah, S., Caitlin, M. C., \& Brien, J. F. (1993). Ethanol neurobehavioural teratogenesis in the guinea pig: Behavioural dysfunction and hippocampal morphological change. Canadian Journal of Physiology and Pharmacology, 71, 776-782.

Abel, E. L. (1982). In utero alcohol exposure and developmental delay of response inhibition. Alcoholism: Clinical and Experimental Research, 6, 376.

Adriani, W., Granstrem, O., Macri, S., Izykenova, G., Dambinova, S., \& Laviola, G. (2004). Behavioral and neurochemical vulnerability during adolescence in mice: Studies with nicotine. Neuropsychopharmacology, 29, 869-878.

Adriani, W., \& Laviola, G. (2003). Elevated levels of impulsivity and reduced place conditioning with $d$-amphetamine: Two behavioral features of adolescence in mice. Behavioral Neuroscience, 117, 695-703.

Alexander, B. K., Coambs, R. B., \&Hadaway, P. F. (1978). The effect of housing and gender on morphine self-administration in rats. Psychopharmacology, 58, 175-179.

American Psychiatric Association (1994). Diagnostic and statistical manual of mental disorders (4th ed.). Washington, DC: Prometheus Books.

Andersen, S. L. (2002). Changes in the second messenger cyclic AMP during development may underlie motoric symptoms in attention deficit/hyperactivity disorder (ADHD). Behavioural Brain Research, 130, 197-201.

Andersen, S. L. (2003). Trajectories of brain development: Point of vulnerability or window of opportunity? Neuroscience and Biobehavioral Reviews, 27, 3-18.

Andersen, S. L., Arvanitogiannis, A., Pliakas, A. M., LeBlanc, C., \& Carlezon, W. A. (2005). Altered responsiveness to cocaine in rats exposed to 
methylphenidate during development. Nature Neuroscience, 5, 13-14.

Babe, K. S., \& Serafin, W. E. (1996). Histamine, bradykinin, and their antagonists. In J. G. Hardman, L. E. Limbird, P. B. Molinoff, R. W. Ruddon, \& A. G. Gilman (Eds.), The pharmacological basis of therapeutics (9th ed., pp. 581-600). New York: McGraw-Hill.

Baer, J. S., Sampson, P. D., Barr, H. M., Connor, P. D., \& Streissguth, A. P. (2003). A 21-year longitudinal analysis of the effects of prenatal alcohol exposure on young adult drinking. Archives of General Psychiatry, 60, 377-385.

Baglenova, J., Birru, S., Pandiella, N. M., \& Breese, C. R. (2004). An assessment of the long-term developmental and behavioral teratogenicity of prenatal nicotine exposure. Behavioural Brain Research, 150, 159-170.

Barratt, E. S., \& Patton, J. H. (1983). Impulsivity: Cognitive, behavioral and psychophysiological correlates. In M. Zuckerman (Ed.), Biological basis of sensation seeking, impulsivity and anxiety (pp. 77-116). Hillsdale, NJ: Lawrence Erlbaum Associates, Inc.

Bates, M. E., Bowden, S. C., \& Barry, D. (2002). Neurocognitive impairment associated with alcohol use disorders: Implications for treatment. Experimental and Clinical Psychopharmacology, 10, 193-212.

Baumann, M. H., Raley, T. S., Partilla, J. S., \& Rothman, R. B. (1993). Biosynthesis of dopamine and serotonin in the rat brain after repeated cocaine injections: A microdissection mapping study. Synapse, 14, 40-50.

Beatty, W. W., Katzung, V. M., Moreland, V. J., \& Nixon, S. J. (1995). Neuropsychological performance of recently abstinent alcoholics and cocaine abusers. Drug and Alcohol Dependence, 37, 247-253.

Bechara, A., \& Damasio, H. (2002). Decision-making and addiction (Part I): Impaired activation of somatic states in substance dependent individuals when pondering decisions with negative future consequences. Neuropsychologia, 40, 1675-1689.

Bechara, A., Dolan, S., Denburg, N., Hindes, A., Anderson, S. W., \& Nathan, P. E. (2001). Decision-making deficits, linked to a dysfunctional ventromedial prefrontal cortex, revealed in alcohol and stimulant abusers. Neuropsychologia, 39, 376-389.

Bechara, A., Tranel, D., \& Damasio, H. (2000). Characterization of the decision-making deficit of patients with ventromedial prefrontal cortex lesions. Brain, 123, 2189-2202.
Belej, T., Maji, D., Sioutis, S., Barros, H. M. T., \& Nobrega, J. N. (1996). Changes in serotonin and norepinephrine uptake sites after chronic cocaine: Pre- vs. post-withdrawal effects. Brain Research, 736, 287-296.

Bennett, A. J., Lesch, K. P., Heils, A., Long, J. C., Lorenz, J. G., Shoaf, S. E. et al. (2002). Early experience and serotonin transporter gene variation interact to influence primate CNS function. Molecular Psychiatry, 7, 118-122.

Bickel, W. K., \& Marsch, D. M. (2001). Toward a behavioral economic understanding of drug dependence: Delay discounting processes. Addiction, 96, 73-86.

Birrell, J. M., \& Brown, V. J. (2000). Medial frontal cortex mediates perceptual attentional set shifting in the rat. Journal of Neuroscience, 20 (11), 4320-4324.

Bizot, J. C., Le Bihan, C., Puech, A. J., Hamon, M., \& Thiebot, M.-H. (1996). Serotonin and tolerance to delay of reward in rats. Psychopharmacology, 146, 400-412.

Blanchard, R. J., Hebert, M. A., Dulloog, L., Kaawaloa, N., Nishimura, O., \& Blanchard, D. C. (1998). Acute cocaine effects on stereotypy and defense: An ethnoexperimental approach. Neuroscience and Biobehavioral Reviews, 23, 179-188.

Block, R. I., Erwin, W. J., \& Ghoneim, M. M. (2002). Chronic drug use and cognitive impairments. Pharmacology, Biochemistry and Behavior, 73, 491-504.

Bolla, K. I., Funderburk, F. R., \& Cadet, J. L. (2000). Differential effects of cocaine and cocaine alcohol on neurocognitive performance. Neurology, 54, 2285-2292.

Bowden, S. C., Crews, F. T., Bates, M. E., Fals-Stewart, W., \& Ambrose, M. L. (2001). Neurotoxicity and neurocognitive impairments with alcohol and drug-use disorders: Potential roles in addiction and recovery. Alcoholism: Clinical and Experimental Research, 25, 317-321.

Boyle, A. E., Gill, K., Smith, B. R., \& Amit, Z. (1991). Differential effects of an early housing manipulation on cocaine-induced activity and self-administration in laboratory rats. Pharmacology, Biochemistry and Behavior, 39, 269-274.

Bozarth, M. A., Murray, A., \& Wise, R. A. (1989). Influence of housing conditions on the acquisition of intravenous heroin and cocaine self-administration in rats. Pharmacology, Biochemistry and Behavior, 33, 903-907. 
Bozarth, M. A., \&Wise, R. A. (1985). Toxicity associated with long-term intravenous heroin and cocaine selfadministration in the rat. Journal of the American Medical Association, 254, 81-83.

Brodsky, B. S., Oquendo, M., Ellis, S. P., Haas, G. L., Malone, K. M., \& Mann, J. J. (2001). The relationship of childhood abuse to impulsivity and suicidal behavior in adults with major depression. American Journal of Psychiatry, 158, 1871-1877.

Brooks, S. P., Hennebry, G., McAlpin, G. P., Norman, G., \& Little, H. J. (2002). Nimodipine prevents the effects of ethanol in tests of memory. Neuropsychopharmacology, 42, 577-585.

Brunner, D., \& Hen, R. (1997). Insights into the neurobiology of impulsive behavior from serotonin receptor knockout mice. Annals of New York Academy of Sciences, 836, 81-105.

Buka, S. L., Shenessa, E. D., \& Niaura, R. (2003). Elevated risk of tobacco dependence among offspring of mothers who smoked during pregnancy: A 30-year prospective study. American Journal of Psychiatry, 160, 1978-1984.

Burchett, S. A., \& Bannon, M. J. (1997). Serotonin, dopamine, and norepinephrine transporter to mRNAs: Heterogeneity of distribution and response to "binge" cocaine administration. Molecular Brain Research, 49, 95-102.

Cardinal, R. N., Pennicott, D. R., Sugathapaia, C. L., Robbins, T. W., \& Everitt, B. J. (2001). Impulsive choice induced in rats by lesions of the nucleus accumbens core. Science, 292, 2499-2501.

Cardinal, R. N., Robbins, T. W., \& Everitt, B. J. (2000). The effects of $d$-amphetamine, chlordiazepoxide, $\alpha$-flupenthixol and behavioural manipulations on choice of signalled and unsignalled delayed reinforcement in rats. Psychopharmacology, 152, 362-375.

Carlezon, W. A., \& Nestler, E. J. (2002). Elevated levels of GluR1 in the midbrain: A trigger for sensitization to drugs of abuse? Trends in Neuroscience, 25, 610-615.

Chambers, R. A., \& Potenza, M. N. (2003). Neurodevelopment, impulsivity, and adolescent gambling. Journal of Gambling Studies, 19, 53-84.

Chen, K., \& Kandel, D. B. (2002). Relationship between extent of cocaine use and dependence among adolescents and adults in the United States. Drug and Alcohol Dependence, 68, 65-85.

Chen, W. J., Maier, S. E., \& West, J. R. (1997). Prenatal alcohol treatment attenuates postnatal cocaine-induced elevation of dopamine concentration in nucleus accumbens: A preliminary study. Neurotoxicology and Teratology, 19, 39-46.

Choong, K., \& Shen, R. (2004). Prenatal ethanol exposure alters the postnatal development of the spontaneous electrical activity of dopamine neurons in the ventral tegmental area. Neuroscience, 126, 1083-1091.

Chow, T. W. (2000). Personality in frontal lobe disorders. Current Psychiatry Reports, 12, 446-451.

Chudasama, Y., Bussey, T. J., \& Muir, J. L. (2001). Effects of selective thalamic and prelimbic cortex lesions on two types of visual discrimination and reversal learning. European Journal of Neuroscience, 14, 1009-1020.

Chudasama, Y., \& Muir, J. L. (2001). Visual attention in the rat: A role for the prelimbic cortex and thalamic nuclei? Behavioral Neuroscience, 115, 417-428.

Chugani, H. R., Phelps, M. E., \& Mazziotta, J. C. (1987). Positron emission tomography study of human brain functional development. Annals of Neurology, 322, 487-497.

Cloninger, C. R., Svarkic, D. M., \& Przybeck, T. R. (1993). A psychobiological model of temperament and character. Archives of General Psychiatry, 50, 975-990.

Cohen, J. D., \& Servan-Schreiber, D. (1992). Context, cortex, and dopamine: A connectionist approach to behavior and biology in schizophrenia. Psychological Review, 99, 45-77.

Cole, B. J., \& Robbins, T. W. (1987). Dissociable effects of lesions to the dorsal or ventral noreadrenergic bundle on the acquisition, performance, and extinction of aversive conditioning. Behavioral Neuroscience, 101, 476-488.

Collins, S. L., \& Izenwasser, S. (2002). Cocaine differentially alters behavior and neurochemistry in periadolescent versus adult rats. Developmental Brain Research, 138, 27-34.

Collins, S. L., \& Izenwasser, S. (2004). Chronic nicotine differentially alters cocaine-induced locomotor activity in adolescent vs. adult male and female rats. Neuropharmacology, 46, 349-362.

Crabbe, J. C., Phillips, T. J., Buck, K. J., Cunningham, C. L., \& Belknap, J. K. (1999). Identifying genes for alcohol and drug sensitivity: Recent progress and future directions. Trends in Neuroscience, 22, 173-179.

Creese, I., \& Iversen, S. D. (1974). The role of forebrain dopamine systems in amphetamine induced stereotyped behaviour in the rat. Psychopharmacology, 239, 345-357. 
Cunningham, C. L., Paris, J. M., \& Goeders, N. E. (1992). Chronic cocaine enhances serotonin autoregulation and serotonin uptake binding. Synapse, 11, 112-123.

Dalley, J. W., Theobald, D. E., Eagle, D. M., Passetti, F., \& Robbins, T. W. (2002a). Deficits in impulse control associated with tonically-elevated serotonergic function in rat prefrontal cortex. Neuropsychopharmacology, 26, 716-728.

Dalley, J. W., Theobald, D. E., Pereira, E. A., Li, P. M., \& Robbins, T. W. (2002b). Specific abnormalities in serotonin release in the prefrontal cortex of isolationreared rats measured during behavioural performance of a task assessing visuospatial attention and impulsivity. Psychopharmacology, 164, 329-340.

Deatherage, G. (1972). Effects of housing density on alcohol intake in the rat. Physiology and Behavior, 9, 55-57.

Deleon, K. R., Grimes, J. M., Conor, D. F., \& Melloni, R. H. (2002). Adolescent cocaine exposure and offensive aggression: Involvement of serotonin neural signaling and innervation in male Syrian hamsters. Behavioural Brain Research, 113, 211-220.

Devenport, D. L., \& Merriman, V. J. (1983). Ethanol and behavioral variability in the radial-arm maze. Psychopharmacology, 79, 21-24.

de Wit, H., Crean, J., \& Richards, J. B. (2000). Effects of $d$-amphetamine and ethanol on a measure of behavioral inhibition in humans. Behavioral Neuroscience, 114, 830-837.

de Wit, H., Enggasser, J. L., \& Richards, J. B. (2002). Acute administration of $d$-amphetamine decreases impulsivity in healthy volunteers. Neuropsychopharmacology, 27, 813-825.

Di Ciano, P., Blaha, C. D., \& Phillips, A. G. (1996). Changes in dopamine oxidation currents in the nucleus accumbens during unlimited-access selfadministration of $d$-amphetamine in rats. Behavioural Pharmacology, 7, 714-729.

Dobbings, J., \& Sands, J. (1979). Comparative aspects of the brain growth spurt. Early Human Development, 3, 79-83.

Doty, P., \& de Wit, H. (1995). Effect of setting on the reinforcing and subjective effects of ethanol in social drinkers. Psychopharmacology, 118, 19-27.

Driscoll, D. C., Streissguth, A. P., \& Riley, E. P. (1990). Prenatal alcohol exposure: Comparability of effects in humans and experimental animals. Neurotoxicology and Teratology, 12, 231-237.

Dworkin, S. I., Co, C., \& Smith, J. E. (1995). Rat brain neurotransmitter turnover rates altered during withdrawal from chronic cocaine administration. Brain Research, 682, 116-126.

Evenden, J. L. (1998). The pharmacology of impulsive behaviour in rats: IV. The effects of selective serotonergic agents on a paced fixed consecutive number schedule. Psychopharmacology, 140, 319-330.

Evenden, J. L. (1999). Impulsivity: A discussion of clinical and experimental findings. Journal of Psychopharmacology, 13, 180-192.

Evenden, J. L., \& Ryan, C. N. (1996). The pharmacology of impulsive behaviour in rats: The effects of drugs on response choice with varying delays of reinforcement. Psychopharmacology, 128, 161-170.

Evenden, J. L., \& Ryan, C. N. (1999). The pharmacology of impulsive behaviour in rats: VI. The effects of ethanol and selective serotonergic drugs on response choice with varying delays of reinforcement. Psychopharmacology, 146, 413-421.

Everitt, B. J., Dickinson, A., \& Robbins, T. W. (2001). The neuropsychological bases of addictive behaviour. Brain Research Reviews, 36, 129-138.

Everitt, B. J., Parkinson, J. A., Olmstead, M. C., Arroyo, M., Robledo, P., \& Robbins, T. W. (1999). Associative processes in addiction and reward. The role of amygdala-ventral striatal subsystems. Annals of New York Academy of Sciences, 877, 412-438.

Everitt, B. J., \& Robbins, T. W. (2000). Second-order schedules of drug reinforcement in rats and monkeys: Measurement of reinforcing efficacy and drug-seeking behavior. Psychopharmacology, 153, $17-30$.

Everitt, B. J., \& Wolf, M. E. (2002). Psychomotor stimulant addiction: A neural systems perspective. Journal of Neuroscience, 22, 3312-3320.

Fein, G., Di Sclafani, V., \& Meyerhoff, D. J. (2002). Prefrontal cortical volume reduction associated with frontal cortex function deficit in 6-week abstinent crack-cocaine dependent men. Drug and Alcohol Dependence, 68, 87-93.

Feola, T. W., de Wit, H., \& Richards, J. B. (2000). Effects of $d$-amphetamine and alcohol on a measure of behavioral inhibition in rats. Behavioral Neuroscience, 114, 838-848.

Fillmore, M. T., \& Rush, C. R. (2002). Impaired inhibitory control of behavior in chronic cocaine users. Drug and Alcohol Dependence, 66, 265-273.

Fillmore, M. T., \& Van Selst, M. (2002). Constraints on information processing under alcohol in the context of response execution and response suppression. Experimental and Clinical Psychopharmacology, 10, $417-424$. 
Finn, P. R., Justus, A. N., Mazas, C. A., \& Steinmetz, J. E. (1999). Working memory, executive processes and the effects of alcohol on go/no-go learning: Testing a model of behavioural regulation and impulsivity. Psychopharmacology, 146, 465-472.

Fleckstein, A. E., Haughey, H. M., Metzger, R. R., Kokoshka, J. M., Riddle, E. L., Hanson, J. E. et al. (1999). Differential effects of psychostimulants and related agents on dopaminergic and serotonergic transporter function. European Journal of Pharmacology, 382, 45-49.

Fletcher, P. J. (1993). A comparison of the effects of dorsal or median raphe injections of 8-OH-DPAT in three operant tasks measuring response inhibition. Bebavioural Brain Research, 54, 187-197.

Franklin, T. R., Acton, P. D., Maldjian, J. A., Gray, J. D., Croft, J. R., Dackis, C. A. et al. (2002). Decreased gray matter concentration in the insular, orbitofrontal, cingulate, and temporal cortices of cocaine patients. Biological Psychiatry, 51, 134-142.

Garcia-Moreno, L. M., Conejo, N. M., Capilla, A., Carci-Sanchez, O., Senderek, K., \& Arias, J. L. (2002). Chronic ethanl intake and object recognition in young and adult rats. Progress in NeuroPsychopharmacology and Biological Psychiatry, 26, 831-837.

Gawin, F. H., \& Ellinwood, E. H. (1988). Cocaine and other stimulants: Actions, abuse, and treatment. New England Journal of Medicine, 318, 1173-1181.

Gendle, M. H., Strawderman, M. S., Mactutus, C. F., Booze, R. M., Levistsky, D. A., \& Strupp, B. J. (2003). Impaired sustained attention and altered reactivity to errors in an animal model of prenatal cocaine exposure. Developmental Brain Research, 147, 85-96.

Gerbing, D. W., Ahadi, S. A., \& Patton, J. H. (1987). Toward a conceptualization of impulsivity: Components across the behavioral and self-report domains. Multivariate Behavioral Research, 22, 357-379.

Glatt, S. J., Trksak, G. H., Cohen, O. S., Simeone, B. P., \& Jackson, D. (2004). Prenatal cocaine exposure decreases nigrostriatal dopamine release in vitro: Effects of age and sex. Synapse, 53, 74-89.

Goldstein, R. Z., \& Volkow, N. D. (2002). Drug addiction and its underlying neurobiological basis: Neuroimaging evidence for the involvement of the frontal cortex. American Journal of Psychiatry, 159, $1642-1652$.

Grant, S., Contoreggi, C., \& London, E. D. (2000). Drug abusers show impaired performance in a laboratory test of decision-making. Neuropsychologia, 38, 1180-1187.

Hall, F. S. (1998). Social deprivation of neonatal, adolescent and adult rats has distinct neurochemical and behavioral consequences. Critical Reviews in Neurobiology, 12, 129-162.

Hall, F. S., Huang, S., Fong, G. W., Pert, A., \& Linnoila, M. (1998a). Effects of isolation-rearing on locomotion, anxiety and responses to ethanol in Fawn Hooded and Wistar rats. Psychopharmacology, 139, 203-209.

Hall, F. S., Huang, S., Fong, G. W., Pert, A., \& Linnoila, M. (1998b). Effects of isolation-rearing on voluntary consumption of ethanol, sucrose and saccharin solutions in Fawn Hooded and Wistar rats. Psychopharmacology, 139, 210-216.

Harrison, A. A., Everitt, B. J., \& Robbins, T. W. (1997). Central 5-HT depletion enhances impulsive responding without affecting the accuracy of attentional performance: Interactions with dopaminergic mechanisms. Psychopharmacology, 133, 329-342.

Harrison, P. A., Fulkerson, J. A., \& Beebe, T. J. (1997). Multiple substance use among adolescent physical and sexual abuse victims. Child Abuse and Neglect, 21, 529-539.

Harrison, P. A., Fulkerson, B. A., \& Beebe, T. J. (2003). DSM-IV substance use disorder criteria for adolescents: A critical examination based on a statewide school survey. American Journal of Psychiatry, 155, 486-492.

Harvey, J. A. (2004). Cocaine effects on the developing brain: Current status. Neuroscience and Biobehavioral Reviews, 27, 751-764.

Hayward, M. L., Martin, A. E., Brein, J. F., Dringenberg, H. C., Olmstead, M. C., \& Reynolds, J. N. (2004). Chronic prenatal ethanol exposure impairs conditioned responding and enhances GABA release in the hippocampus of the adult guinea pig. Journal of Pharmacology and Experimental Therapeutics, 308, 644-650.

Heinz, A., Mann, K., Weinberger, D. R., \& Goldman, D. (2001). Serotonergic dysfunction, negative mood states, and response to alcohol. Alcoholism: Clinical and Experimental Research, 25, 487-495.

Hellemans, K. G. C., Nobrega, J. N., \& Olmstead, M. C. (2005). Early environmental experience alters baseline and ethanol-induced cognitive impulsivity: Relationship to forebrain $5-\mathrm{HT}_{1 \mathrm{~A}}$ receptor binding. Behavioural Brain Research, 159, 207-220. 
Hellemans, K. G. C., Shaham, Y., \& Olmstead, M. C. (2002). Dissociable effects of acute and chronic opiate abstinence on drug-seeking and drug-taking. Canadian Journal of Experimental Psychology, 56, 241-252.

Hellstrom-Lindahl, E., \& Noberg, A. (2002). Smoking during pregnancy: A way to transfer the addiction to the next generation? Respiration, 69, 289-293.

Higley, J. D., \& Linnoila, M. (1997). A nonhuman primate model of excessive alcohol intake. Personality and neurobiological parallels of type Iand type II-like alcoholism. Recent Developments in Alcohol, 13, 191-219.

Hill, S. Y., \& Powell, B. J. (1976). Cocaine and morphine self-administration: Effects of differential rearing. Pharmacology, Biochemistry and Behavior, 5, 701-704.

Hoaken, P. N., Assaad, J. M., \& Phil, R. O. (1998). Cognitive functioning and the inhibition of alcohol-induced aggression. Journal of Studies on Alcohol, 59, 599-607.

Hobbs, W. R., Rall, T. W., \& Verdoorn, T. A. (1996). Hypnotics and sedatives: Ethanol. In J. G. Hardman, L. E. Limbird, P. B. Molinoff, R. W. Ruddon, \& A. Goodman Gilman (Eds.), Goodman and Gilman's the pharmacological basis of therapeutics (9th ed., pp. 361-398). New York: McGraw-Hill.

Homberg, J., van den Akker, M., Raaso, H., Wardeh, G., Binnekade, R., Schoffelmeer, A. N. M. et al. (2002). Enhanced motivation to self-administer cocaine is predicted by self-grooming behaviour and relates to dopamine release in the rat medial prefrontal cortex and amygdala. European Journal of Neuroscience, 15, 1542-1550.

Hommer, D. W., Andreasen, P., Rio, D., Williams, W., Ruttimann, Y., Momenan, R. et al. (1997). Effects of $\mathrm{m}$-chlorophenylpiperazine on regional brain glucose utilization: A positron emission tomographic comparison of alcoholic and control subjects. Journal of Neuroscience, 17, 2796-2806.

Howes, S. R., Dalley, J. W., Morrison, C. H., Robbins, T. W., \& Everitt, B. J. (2000). Leftward shift in the acquisition of cocaine self-administration in isolation-reared rats: Relationship to extracellular levels of dopamine, serotonin and glutamate in the nucleus accumbens and amygdala-striatal FOS expression. Psychopharmacology, 151, 55-63.

Hutcheson, D. M., Everitt, B. J., Robbins, T. W., \& Dickinson, A. (2001). The role of withdrawal in heroin addiction: Enhances reward or promotes avoidance? Nature Neuroscience, 4, 943-947.
Hyman, S. E., \& Malenka, R. C. (2001). Addiction and the brain: The neurobiology of compulsion and its persistence. Nature Reviews, 2, 695-703.

Iqbal, U., Dringenberg, H. C., Brien, J. F., \& Reynolds, J. N. (2004). Chronic prenatal ethanol exposure alters hippocampal $\mathrm{GABA}(\mathrm{A})$ receptors and impairs spatial learning in the guinea pig. Behavioural Brain Research, 150, 117-125.

Jacobs, E. H., Smit, A. B., De Vries, T., \& Schoffelmeer, A. N. M. (2003). Neuroadapative effects of active versus passive drug administration in addiction research. Trends in Pharmacological Sciences, 24, 566-573.

Jacobsen, L. K., Staley, J. K., Malison, R. T., Zoghbi, S. S., Kosten, T. R., \& Innis, R. B. (2000). Elevated central serotonin transporter binding availability in acutely abstinent cocaine-dependent patients. American Journal of Psychiatry, 157, 1134-1140.

Jentsch, J. D., Olausson, P., De La Garza, R., \& Taylor, J. R. (2002). Impairments of reversal learning and response perseveration after repeated, intermittent cocaine administrations to monkeys. Neuropsychopharmacology, 26, 183-190.

Jentsch, J. D., \& Taylor, J. R. (1999). Impulsivity resulting from frontostriatal dysfunction in drug abuse: Implications for the control of behavior by reward-related stimuli. Psychopharmacology, 146, 373-390.

Jentsch, J. D., \& Taylor, J. R. (2003). Sex-related differences in spatial divided attention and motor impulsivity in rats. Behavioral Neuroscience, 117, 76-83.

Johnson, R. G., Fiorella, D., \& Rabin, R. A. (1993). Effects of chronic cocaine administration on the serotonergic system in the rat brain. Pharmacology, Biochemistry and Behavior, 46, 289-293.

Kalivas, P. W., Sorg, B. A., \& Hooks, M. S. (1993). The pharmacology and neural circuitry of sensitization to psychostimulants. Behavioural Pharmacology, 4, 315-334.

Kandel, D. B., Yamaguchi, K., \& Chen, K. (1992). Stages of progression in drug involvement from adolescence to adulthood: Further evidence for the gateway theory. Journal of Studies on Alcohol, 53, 447-457.

Kane, V. G., Fu, Y., Matta, S. G., \& Sharp, B. M. (2004). Gestational nicotine exposure attenuates nicotine-stimulated dopamine release in the nucleus accumbens shell of adolescent Lewis rats. Journal of Pharmacology and Experimental Therapeutics, 308, 521-528. 
Kazmaier, K., Butcher, R. E., Senter, R. J., \& Stutz, R. M. (1973). Rearing conditions and ethanol consumption by rats. Quarterly Journal of Studies on Alcohol, 34, 520-524.

Keller, R. W., LeFevre, R., Raucci, J., \& Carlson, J. N. (1996). Enhanced cocaine self-administration in adult rats prenatally exposed to cocaine. Neuroscience Letters, 205, 153-156.

Kelley, A. E., \& Berridge, K. C. (2002). The neuroscience of natural rewards: Relevance to addictive drugs. Journal of Neuroscience, 22, 3306-3311.

Kilbey, M. M., \& Ellinwood, E. H. (1977). Chronic administration of stimulant drugs: Response modification. In E. H. Ellinwood (Ed.), Advances in behavioural biology (pp. 409-429). New York: Plenum Press.

Kirby, K. N., Petry, N. M., \& Bickel, W. K. (1999). Heroin addicts have higher discount rates for delayed rewards than non-drug using controls. Journal of the Experimental Analysis of Behavior, $128,78-87$.

Kish, S. J. (2002). How strong is the evidence that brain serotonin neurons are damaged in human users of Ecstasy? Pharmacology, Biochemistry and Behavior, 71, 845-855.

Kleven, M. S., Woolverton, W. L., \& Seiden, L. (1988). Lack of long-term monoamine depletions following repeated or continuous exposure to cocaine. Brain Research Bulletin, 21, 233-237.

Klitzman, R. L., Pope, H. G., Jr., \& Hudson, J. I. (2000). MDMA ("Ecstasy") abuse and highrisk sexual behaviors among 169 gay and bisexual men. American Journal of Psychiatry, 157, 1162-1164.

Kodituwakku, P. W., May, P. A., Clericuuzio, C. L., \& Weers, D. (2001). Emotion-related learning in individuals prenatally exposed to alcohol: An investigation of the relation between set shifting, extinction of responses, and behaviour. Neuropsychologia, 39, 699-708.

Koob, G. F., \& Le Moal, M. (2001). Drug addiction, dysregulation of reward, and allostasis. Neuropsychopharmacology, 24, 97-129.

Kuczenski, R., \& Segal, D. S. (1997). An escalating dose/multiple high-dose binge pattern of amphetamine administration results in differential changes in the extracellular dopamine response profiles in caudate-putamen and nucleus accumbens. Journal of Neuroscience, 17, 4441-4447.

Lau, M. A., Pihl, R. O., \& Peterson, J. B. (1995). Provocation, acute alcohol intoxication, cognitive performance and aggression. Journal of Abnormal Psychology, 104, 150-155.

Laviola, G., Macri, S., Morley-Fletcher, S., \& Adriani, W. (2003). Risk-taking behavior in adolescent mice: Psychobiological determinants and early epigenetic influence. Neuroscience and Biobehavioral Revierws, 27, 19-31.

Laviola, G., Wood, R. D., Kuhn, C., Francis, R., \& Spear, L. P. (1995). Cocaine sensitization in periadolescent and adult rats. Journal of Pharmacology and Experimental Therapeutics, 275, 345-357.

Lesch, K. P., \& Merschdorf, U. (2000). Impulsivity, aggression, and serotonin: A molecular psychobiological perspective. Behavioural Sciences and the Law, 18, 581-604.

Leshner, A. I. (2000). Vulnerability to addiction: New research opportunities. American Journal of Medical Genetics, 96, 590-591.

Lindholm, S., Rosin, A., Dahlin, I., Georgieva, J., \& Frank, J. (2001). Ethanol administration potentiates cocaine-induced dopamine levels in the rat nucleus accumbens. Brain Research, 915, 176-184.

Little, K. Y., McLaughlin, D. P., Zhang, L., Livermore, C. S., Dalack, G. W., McFinton, P. R. et al. (1998). Cocaine, ethanol, and genotype effects on human midbrain serotonin transporter binding sites and mRNA levels. American Journal of Psychiatry, 155, 207-213.

Little, K. Y., Patel, U. N., Clark, T. B., \& Butts, J. D. (1996). Alterations of brain dopamine and serotonin levels in cocaine users: A preliminary report. American Journal of Psychiatry, 153, 1216-1218.

London, E. D., Ernst, M., Grant, S., Bonson, K., \& Weinstein, A. (2000). Orbitofrontal cortex and human drug abuse: Functional imaging. Cerebral Cortex, 10, 334-342.

Lovinger, D. M. (1999). 5-HT-sub-3 receptors and the neural actions of alcohol: An increasingly exciting topic. Neurochemistry International, 35, 125-130.

MacDonald, T. K., Fong, G. T., Zanna, M. P., \& Martineau, A. M. (2000). Alcohol myopia and condom use: Can alcohol intoxication be associated with more prudent behavior? Journal of Personality and Social Psychology, 78, 605-619.

MacDonald, T. K., Zanna, M. P., \& Fong, G. T. (1996). Why comon sense goes out the window: Effects of alcohol on intentions to use condoms. Personality and Social Psychology Bulletin, 22, $763-775$.

Madden, G. J., Petry, N. M., Badger, G. J., \& Bickel, W. K. (1997). Impulsive and self-control choices in

\section{8}


opioid-dependent patients and non-drug-using control participants: Drug and monetary rewards. Experimental and Clinical Psychopharmacology, 5, 256-262.

Maisonneuve, I. M., \& Kreek, M. J. (1994). Acute tolerance to the dopamine release induced by a binge pattern of cocaine administration in male rats: An in-vivo microdialysis study. Journal of Pharmacology and Experimental Therapeutics, 268, 916-921.

Marinelli, M., \& Piazza, P. V. (2002). Interaction between glucocorticoid hormones, stress and psychostimulant drugs. European Journal of Neuroscience, 16, 387-394.

Markou, A. (1998). Neurobiological similarities in depression and drug dependence: A self-medication hypothesis. Neuropsychopharmacology, 18, 135-174.

Markou, A., Weiss, F., Gold, L. H., Caine, S. B., Schulteis, G., \& Koob, G. F. (1993). Animal models of drug craving. Psychopharmacology, 112, 163-182.

Martensson, L. (1984). The pregnant rabbit, guinea pig, sheep and rhesus monkey as models in reproductive physiology. European Journal of Obstetrics and Gynecological Reproductive Biology, 18, 169-182.

Mattson, S. N., \& Riley, E. P. (1998). A review of the neurobehavioral deficits in children with Fetal Alcohol Syndrome or prenatal exposure to alcohol. Alcoholism: Clinical and Experimental Research, 22, 279-294.

Mattson, S. N., Schoenfeld, A. M., \& Riley, E. P. (2001). Teratogenic effects of alcohol on brain and behavior. Alcohol Research and Health, 25, 185-191.

McCann, U. D., Ridenour, A., Shaham, Y., \& Ricaurte, G. A. (1997). Serotonin neurotoxicity after $(+)$ 3,4-methlyenedioxymethamphetamine (MDMA: "Ecstasy"): A controlled study in humans. Neuropsychopharmacology, 10, 129-138.

McClure, G., \& McMillan, D. (1997). Effects of drugs on response duration differentiation: VI. Differential effects of differential reinforcement of low rates of responding schedules. Journal of Pharmacology and Experimental Therapeutics, 281, 1368-1380.

Melega, W. P., Quintana, J., Raleigh, M. J., Stout, D. B., Yu, D. C., Lin, K. P. et al. (1996). $6-\left[{ }^{18}\right]$ fluoro- $[\mathrm{sal}]^{1}$-DOPA-PET studies show partial reversibility of long-term effects of chronic amphetamine in monkeys. Synapse, 22, 63-69.

Miller, L. (1992). Impulsivity, risk-taking, and the ability to synthesize fragmented information after frontal lobectomy. Neuropsychologia, 30, 69-79.
Mitchell, S. H. (1999). Measures of impulsivity in cigarette smokers and non-smokers. Psychopharmacology, 146, 455-464.

Moeller, F. G., Dougherty, D. M., Barratt, E. S., Oderinde, V., Mathias, C. W., Harper, R. A. et al. (2002). Increased impulsivity in cocaine dependent subjects independent of antisocial personality disorder and aggression. Drug and Alcohol Dependence, 68, 105-111.

Morgan, M. J. (1998). Recreational use of Ecstasy (MDMA) is associated with elevated impulsivity. Neuropsychopharmacology, 19, 252-264.

Morgan, M. J. (2000). Ecstasy (MDMA): A review of its possible persistent psychological effects. Psychopharmacology, 152, 230-248.

Morral, A. R., McCaffrey, D. F., \& Paddock, S. M. (2002). Reassessing the marijuana gateway effect. Addiction, 97, 1493-1504.

Nadal, R., Armario, A., \& Janak, P. H. (2002). Positive relationship between activity in a novel environment and operant ethanol self-administration in rats. Psychopharmacology, 162, 333-338.

Nanson, J. L., \& Hiscock, M. (1990). Attention deficits in children exposed to alcohol prenatally. Alcoholism: Clinical and Experimental Research, 14, 656-661.

Neddens, J., Lesting, J., Dawirs, R. R., \& TeuchertNoodt, G. (2002). An early methampethamine challenge suppresses the maturation of dopamine fibres in the nucleus accumbens of gerbils: On the significance of rearing condition. Journal of Neural Transmission, 109, 141-155.

Nestler, E. J. (2001). Molecular basis of long-term plasticity underlying addiction. Nature Neuroscience, 2, 119-128.

O’Boyle, M., \& Barratt, E. S. (1993). Impulsivity and DSM-III-R personality disorders. Personality and Individual Differences, 14, 609-611.

Olmstead, M. C., Hellemans, K. G. C., \& Paine, T. A. (in press). Alcohol induced impulsivity in rats: An effect of cue salience? Psychopharmacology.

Olmstead, M. C., Lafond, M. V., Everitt, B. J., \& Dickinson, A. (2001). Cocaine-seeking by rats is a goal directed action. Behavioral Neuroscience, 115, 394-402.

Olmstead, M. C., Parkinson, J. A., Miles, F., Everitt, B. J., \& Dickinson, A. (2000). Cocaine-seeking by rats: Regulation, reinforcement and activation. Psychopharmacology, 152, 123-131.

Ornstein, T. J., Iddon, J. L., Baldacchino, A., Sahakian, B. J., London, M., Everitt, B. J. et al. (2000). Profiles 
of cognitive dysfunction in chronic amphetamine and heroin abusers. Neuropsychopharmacology, 23, 113-126.

Ortner, C. N., MacDonald, T. K., \& Olmstead, M. C. (2003). Alcohol intoxication reduces impulsivity in a delay discounting paradigm. Alcohol and Alcoholism, 38, 151-156.

Paine, T. A., Dringenberg, H. C., \& Olmstead, M. C. (2003). Effects of chronic cocaine on impulsivity: Relation to cortical serotonin mechanisms. Behavioural Brain Research, 147, 135-147.

Paine, T. A., McElvie, B., Dringenberg, H. C., \& Olmstead, M. C. (2004). Chronic cocaine impairs reversal learning in the attentional set-shifting paradigm. Society for Neuroscience Abstracts.

Paine, T. A., \& Olmstead, M. C. (2003). Impaired response inhibition and conditional discrimination following acute cocaine administration. Psychopharmacology, 175, 443-450.

Paus, T. (2005). Mapping brain maturation and cognitive development during adolescence. Trends in Cognitive Sciences, 9, 60-68.

Paus, T., Zijdenbos, A., Worsley, K., Collins, D. L., Blumenthal, J., Giedd, J. N. et al. (1999). Structural maturation of neural pathways in children and adolescents: An in vivo study. Science, 283, 1908-1911.

Petry, N. M. (2001). Substance abuse, pathological gambling, and impulsiveness. Drug and Alcohol Dependence, 63, 29-38.

Phillips, G. D., Howes, S. R., Whitelaw, R. B., Robbins, T. W., \& Everitt, B. J. (1994a). Isolation rearing impairs the reinforcing efficacy of intravenous cocaine or intra-accumbens $d$-amphetamine: Impaired response to intra-accumbens D1 and D2/D3 dopamine receptor antagonists. Psychopharmacology, 115, 419-429.

Phillips, G. D., Howes, S. R., Whitelaw, R. B., Wilkinson, L. S., Robbins, T. W., \& Everitt, B. J. (1994b). Isolation rearing enhances the locomotor response to cocaine and a novel environment, but impairs the intravenous self-administration of cocaine. Psychopharmacology, 115, 407-418.

Piazza, P. V., \& Le Moal, M. (1996). Pathophysiological basis of vulnerability to drug abuse: Role of an interaction between stress, glucocorticoids, and dopaminergic neurons. Annual Review of Pharmacology and Toxicology, 36, 359-378.

Pitman, P. K. (1989). Animal models of compulsive behavior. Biological Psychiatry, 26, 189-198.
Poulos, C. X., Parker, J. L., \& Le, A. D. (1996). Dexfenfluramine and 8-OH-DPAT modulate impulsivity in a delay-of-reward paradigm: Implications for a correspondence with alcohol consumption. Behavioural Pharmacology, 7, 395-399.

Poulos, C. X., Parker, J. L., \& Le, D. A. (1998). Increased impulsivity after injected alcohol predicts later alcohol consumption in rats: Evidence for "loss-of-control drinking" and marked individual differences. Behavioral Neuroscience, 112, 1247-1257.

Ramsey, N. F., Niesink, R. J., \& Van Ree, J. M. (1993). Prenatal exposure to morphine enhances cocaine and heroin self-administration in drug-naive rats. Drug and Alcohol Dependence, 33, 41-51.

Randrup, A., \& Scheel-Kruger, J. (1966). Diethyldithiocarbamate and amphetamine stereotype behaviour. Journal of Pharmacy and Pharmacology, 18, 752.

Rapoport, J. L. (1990). Obsessive compulsive disorder and basal ganglia dysfunction. Psychological Medicine, 20, 465-469.

Reneman, L., Booij, J., Schmand, B., van den Brink, W., \& Gunning, B. (2000). Memory disturbances in "Ecstasy" users are correlated with an altered brain serotonin neurotransmission. Psychopharmacology, 148, 322-324.

Reneman, L., Majoie, C. B. L. M., Schmand, B., van den Brink, W., \& den Heeten, G. J. (2001). Prefrontal $\mathrm{N}$-acetylaspartate is strongly associated with memory performance in (abstinent) ecstasy users: Preliminary report. Biological Psychiatry, 50, 550-554.

Richards, J. B., Sabol, K. E., \& de Wit, H. (1999a). Effects of methamphetamine on the adjusting amount procedure, a model of impulsive behavior in rats. Psychopharmacology, 146, 432-439.

Richards, J. B., Zhang, L., Mitchell, S., \& de Wit, H. (1999b). Delay or probability discounting in a model of impulsive behavior: Effect of alcohol. Journal of the Experimental Analysis of Behavior, 71, 121-143.

Richardson, D. P., Byrnes, M. L., Brien, J. F., Reynolds, J. N., \& Dringenberg, H. C. (2002). Impaired acquisition in the water maze and hippocampal long-term potentiation after chronic prenatal ethanol exposure in the guinea pig. European Journal of Neuroscience, 16, 1593-1598.

Ridley, R., Baker, H., \& Weight, M. (1980). Amphetamine disrupts successive but not 
simultaneous visual discriminations in the monkey. Psychopharmacology, 67, 241-244.

Riley, E. P., Lochry, E. A., \& Shapiro, N. R. (1979). Lack of response inhibition in rats prenatally exposed to alcohol. Psychopharmacology, 41, 652-659.

Riley, E. P., Shapiro, N. R., Lochry, E. A., \& Broida, A. P. (1980). Mixed-ratio performance and subsequent extinction in rats prenatally exposed to ethanol. Physiological Psychology, 8, 27-50.

Robbins, T. W., Jones, G. H., \& Wilkinson, L. S. (1996). Behavioural and neurochemical effects of early social deprivation in the rat. Journal of Psychopharmacology, 10, 39-47.

Roberts, D. C. S., Loh, E. A., Baker, G. B., \& Vickers, G. (1994). Lesions of central serotonin systems affect responding on a progressive ratio schedule reinforced by either intravenous cocaine or by food. Pharmacology, Biochemistry and Behavior, 49, 177-182.

Robinson, T. E., \& Berridge, K. C. (1993). The neural basis of drug craving: An incentive-sensitization theory of addiction. Brain Research Reviews, 18, 247-291.

Robinson, T. E., \& Berridge, K. C. (2003). Addiction. Annual Review of Psychology, 54, 53.

Robinson, T. E., Gorny, G., Mitton, E., \& Kolb, B. (2001). Cocaine self-administration alters the morphology of dendrites and dendritic spines in the nucleus accumbens and neocortex. Synapse, 39, 257-266.

Robinson, T. E., \& Kolb, B. (1999). Alterations in the morphology of dendrites and dendritic spines in the nucleus accumbens and prefrontal cortex following repeated treatment with amphetamine or cocaine. European Journal of Neuroscience, 11, 1598-1604.

Rocha, B. A., Mead, A. N., \& Kosofsky, B. E. (2002). Increased vulnerability to self-administer cocaine in mice prentally exposed to cocaine. Psychopharmacology, 163, 221-229.

Rockman, G. E., Hall, A. M., Markert, L. E., \& Glavin, G. B. (1988). Influence of rearing conditions on voluntary ethanol intake and response to stress in rats. Behavioral and Neural Biology, 49, 184-191.

Rogers, R. D., Everitt, B. J., Baldacchino, A., Johnson, A. J., Swainson, R., London, M. et al. (1999). Dissociable deficits in decision-making cognition of chronic amphetamine abusers, opiate abusers, patients with focal damage to prefrontal cortex, and tryptophan-depleted normal volunteers: Evidence for monoaminergic mechanisms. Neuropsychopharmacology, 20, 322-339.
Rossetti, Y., Carboni, E., Stancampiano, R., Sori, P., Pepeu, G., \& Fadda, F. (2002). Bidirectional modulation of spatial working memory by ethanol. Alcoholism: Clinical and Experimental Research, 26, 181-185.

Rudnick, G., \& Wall, S. C. (1992). The molecular mechanism of "ecstasy" $[3,4$ methylenediosymethamphetamine (MDMA)]: Serotonin transporters are targets for MDMA-induced serotonin release. Proceedings of the National Academy of Sciences (USA), 89, 1817-1821.

Ruotsalainen, S., Miettinen, R., MacDonald, E., Koivisto, E., \& Sirvio, J. (2000). Blockade of muscarinic, rather than nicotinic, receptors impairs attention, but does not interact with serotonin depletion. Psychopharmacology, 148, 111-123.

Ryan, L. J., Linder, J. C., Martone, M. E., \& Groves, P. M. (1990). Histological and ultrastructural evidence that $d$-amphetamine causes degeneration in neostriatum and frontal cortex of rats. Brain Research, 518, 67-77.

Sabol, K. E., Richards, J., Layton, K., \& Seiden, L. (1995). Amphetamine analogs have differential effects on DRL 36-s schedule performance. Psychopharmacology, 121, 57-65.

Sahakian, B. J., Robbins, T. W., Morgan, M. J., \& Iversen, S. D. (1975). The effects of psychomotor stimulants on stereotypy and the locomotor activity in socially deprived and control rats. Brain Research, 84, 195-205.

Salvatore, M. F., Hudspeth, O., Arnold, L. E., Wilson, P. E., Stanford, J. A., Mactutus, C. F. et al. (2004). Prenatal cocaine exposure alters potassium-evoked dopamine release dynamics in rat striatum. Neuroscience, 123, 481-490.

Schenk, S., Gorman, K., \& Amit, Z. (1990). Agedependent effects of isolation housing on the selfadministration of ethanol in laboratory rats. Alcohol, 7, 321-326.

Schenk, S., Lacelle, G., Forman, K., \& Amit, Z. (1987). Cocaine self-administration in rats influenced by environmental conditions: Implications for the etiology of drug abuse. Neuroscience Letters, 81, 227-231.

Schenk, S., Robinson, B., \& Amit, Z. (1988). Housing conditions fail to affect the intravenous self-administration of amphetamine. Pharmacology, Biochemistry and Behavior, 31, 59-62.

Schrijver, N. C. A., \& Wurbel, H. (2001). Early social deprivation disrupts attentional, but not affective, shifts in rats. Behavioral Neuroscience, 115, 437-442. 
Schwartz, A. S., \& Marchok, P. L. (1974). Depression of morphine-seeking behaviour by dopamine inhibition. Nature, 248, 257-258.

Scourfield, J., Stevens, D. E., \& Merikangas, K. R. (1996). Substance abuse, comorbidity, and sensation seeking: Gender differences. Comprehensive Psychiatry, 37, 384-392.

Segal, D. S., \& Kuczenski, R. (1997a). Behavioral alterations induced by an escalating dose-binge pattern of cocaine administration. Behavioural Brain Research, 88, 251-260.

Segal, D. S., \& Kuczenski, R. (1997b). Repeated binge exposures to amphetamine and methamphetamine: Behavioral and neurochemical characterization. Journal of Pharmacology and Experimental Therapeutics, 282, 561-573.

Segal, D. S., \& Kuczenski, R. (1999). Escalating dosebinge stimulant exposure: Relationship between emergent behavioral profile and differential caudate-putamen and nucleus accumbens dopamine responses. Psychopharmacology, 142, 182-192.

Shaham, Y., Erb, S., \& Stewart, J. (2000). Stressinduced relapse to heroin and cocaine seeking in rats: A review. Brain Research Reviews, 1.

Shen, R. Y., Hannigan, J. H., \& Kapatos, G. (1999). Prenatal ethanol exposure reduces the activity of adult midbrain dopamine neurons. Alcoholism: Clinical and Experimental Research, 23, 1801-1807.

Singer, L. T., Minnes, S., Short, E., Arendt, R., Farkas, K., Lewis, G. et al. (2004). Cognitive outcomes of preschool children with prenatal cocaine exposure. Journal of the American Medical Association, 291, 2448-2456.

Smith, A. M., Fried, P. A., Hogan, M. J., \& Cameron, I. (2004). Effects of prenatal marijuana on response inhibition: An fMRI study of young adults. Neurotoxicology and Teratology, 26, 533-542.

Smith, R. F. (2003). Animal models of periadolescent substance abuse. Neurotoxicology and Teratology, 25, 291-301.

Sokolowski, J. D., \& Salamone, J. D. (1994). Effects of dopamine depletions in the medial prefrontal cortex on DRL performance and motor activity in the rat. Brain Research, 642, 20-28.

Sowell, E. R., Thompson, P. M., Tessner, K. D., \& Toga, A. W. (2001). Mapping continued brain growth and gray matter density reduction in dorsal frontal cortex: Inverse relationships during postadolescent brain maturation. Journal of Neuroscience, 21, 8819-8829.
Spear, L. P., \& Brake, S. C. (1983). Periadolescence: Age-dependent behavior and psychopharmacological responsivity in rats. Developmental Pyschobiology, 16, 83-109.

Stapleton, J. M., Morgan, M. J., Phillips, R. L., Wong, D. F., Yung, B. C. K., Shaya, E. K. et al. (1995). Cerebral glucose utilization in polysubstance abuse. Neuropsychopharmacology, 13, 22-31.

Steele, C. M., \& Josephs, R. A. (1990). Alcohol myopia. American Psychologist, 45, 921-933.

Stewart, J., \& Badiani, A. (1993). Tolerance and sensitization to the behavioral effects of drugs. Behavioural Pharmacology, 4, 289-312.

Streissguth, A. P., Martin, D. C., Barr, H. M., \& MacGregor-Sandman, B. (1984). Intrauterine alcohol and nicotine exposure: Attention and reaction time in 4-year-old children. Developmental Psychology, 20, 533-541.

Szechtman, H., Eckert, M. J., Tse, W. S., Boersma, J. T., Bonura, C. A., McClelland, J. Z. et al. (2001). Compulsive checking behavior of quinpirole-sensitized rats as an animal model of Obsessive-Compulsive Disorder (OCD): Form and control. Biomedical Central: Neuroscience, 2, 1471-2202.

Szechtman, H., \& Woody, E. (2003). ObsessiveCompulsive Disorder as a disturbance of security motivation. Psychological Review, X, 1-28.

Taylor, J. R., \& Jentsch, J. D. (2001). Repeated intermittent administration of psychomotor stimulant drugs alters the acquisition of Pavlovian approach behavior in rats: Differential effects of cocaine, d-amphetamine and 3,4- methylenedioxymethamphetamine ("Ecstasy"). Biological Psychiatry, 50, 137-143.

Tiffany, S. T. (1990). A cognitive model of drug urges and drug-use behavior: Role of automatic and nonautomatic processes. Psychological Review, 97, 147-168.

Tornatzky, W., \& Miczek, K. A. (1999). Repeated limited access to IV cocaine self-administration: Conditioned autonomic rhythmicity illustrating "predictive homeostasis". Psychopharmacology, 145, 144-152.

Tornatzky, W., \& Miczek, K. A. (2000). Cocaine selfadministration "binges": transition from behavioral and automatic regulation toward homeostatic dysregulation in rats. Psychopharmacology, 148, 289-298.

Unterwald, E. M., Ho, A., Rubenfield, J. M., \& Kreek, M. J. (1994). Time course of the development 
of behavioral sensitization and dopamine receptor up-regulation during binge cocaine administration. Journal of Pharmacology and Experimental Therapeutics, 270, 1387-1397.

Vanderschuren, L. J. M. J., \& Everitt, B. J. (2004). Drug seeking becomes compulsive after prolonged cocaine self-administration. Science, 305, 1017-1019.

Volkow, N. D., \& Fowler, J. S. (2000). Addiction, a disease of compulsion and drive: Involvement of the orbitofrontal cortex. Cerebral Cortex, 10, 318-325.

von Knorring, L., von Knorring, A., Smigan, L., Lindberg, U., \& Edholm, M. (1987). Personality traits in subtypes of alcoholics. Journal of Studies on Alcohol, 48, 523-527.

Vuchinich, R. E., \& Simpson, C. A. (1998). Hyperbolic temporal discounting in social drinkers and problem drinkers. Experimental and Clinical Psychopharmacology, 6, 292-305.

Wade, T. R., de Wit, H., \& Richards, J. B. (2000). Effects of dopaminergic drugs on delayed reward as a measure of impulsive behavior in rats. Psychopharmacology, 150, 90-101.

Weissenborn, R., Robbins, T. W., \& Everitt, B. J. (1997). Effects of medial prefrontal or anterior cingulate cortex lesions on responding for cocaine under fixedratio and second-order schedules of reinforcement in rats. Psychopharmacology, 134, 242-257.

Wenger, G., \& Wright, D. (1990). Behavioral effects of cocaine and its interactions with $\mathrm{D}$-amphetamine and morphine in rats. Pharmacology, Biochemistry and Behavior, 35, 595-600.

White, A. M., Ghia, A. J., Levin, E. D., \& Swartzwelder, H. S. (2000). Binge pattern ethanol exposure in adolescent and adult rats: Differential impact on subsequent responsiveness to ethanol. Alcoholism: Clinical and Experimental Research, 24, 1251-1256.

White, N. M. (1996). Addictive drugs as reinforcers: Multiple partial actions on memory systems. Addiction, 91, 921-949.

Wilcott, R. C. (1982). Frontal lesions and the rate of operant behavior. Physiological Psychology, 10, 371-375.
Williams, B. R., Ponesse, J. S., Schachar, R. J., Logan, G. D., \& Tannock, R. (1999). Development of inhibitory control across the life span. Developmental Psychology, 35, 205-213.

Wilmouth, C. E., \& Spear, L. P. (2004). Adolescent and adult rats' aversion to flavors previously paired with nicotine. Annals New York Academy of Sciences, 1021, 462-464.

Wilson, J. M., Nobrega, J. N., Corrigall, W. A., Coen, K. M., Shannak, K., \& Kish, S. J. (1994). Amygdala dopamine levels are markedly elevated after self- but not passive-administration of cocaine. Brain Research, 668, 39-45.

Wise, R. A. (1988). The neurobiology of craving: Implications for the understanding and treatment of addiction. Journal of Abnormal Psychology, 97, 118-132.

Wise, R. A. (1996). Neurobiology of addiction. Current Opinion in Neurobiology, 6, 243-251.

Wise, R. A. (1999). Cognitive factors in addiction and nucleus accumbens function: Some hints from rodent models. Psychobiology, 27, 300-310.

Wise, R. A. (2000). Addiction becomes a brain disease. Neuron, 26, 27-33.

Wise, R. A., \& Bozarth, M. A. (1987). A psychomotor stimulant theory of addiction. Psychological Review, 94, 469-492.

Woolverton, W. L., Kandel, D. B., \& Schuster, C. R. (1978). Effects of repeated administration of cocaine on schedule-controlled behavior of rats. Pharmacology, Biochemistry and Behavior, 9, 327-337.

Yin, H. H., Knowlton, B. J., \& Balleine, B. W. (2004). Lesions of dorsolateral striatum preserve outcome expectancy but disrupt habit formation in instrumental learning. European Journal of Neuroscience, 19, 181-189.

Zhang, Y., Schlussman, S. D., Ho, A., \& Kreek, M. J. (2001). Effect of acute binge cocaine on levels of extracellular dopamine in the caudate putamen and nucleus accumbens in male C57BL/6J and 129/J mice. Brain Research, 923, $172-177$. 